\title{
Two large-effect QTLs, Ma and Ma3, determine genetic potential for acidity in apple fruit: breeding insights from a multi-family study
}

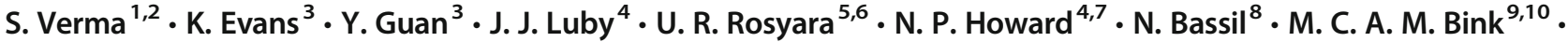 \\ W. E. van de Weg $^{11}$. C. P. Peace ${ }^{1}$
}

Received: 23 September 2018 / Revised: 23 January 2019 / Accepted: 28 January 2019 / Published online: 12 February 2019

(C) The Author(s) 2019

\begin{abstract}
Acidity is a critical component of the apple fruit consumption experience. In previous biparental family studies, two large-effect acidity QTLs were reported using freshly harvested fruit. Objectives of this study were to determine the number and location of QTLs for acidity variation in a large apple breeding program and ascertain the quantitative effects and breeding relevance of QTL allelic combinations at harvest and after commercially relevant periods of cold storage. Pedigree-connected germplasm of 16 full-sib families representing nine important breeding parents, genotyped for the 8K SNP array, was assessed for titratable acidity at harvest and after 10 - and 20-week storage treatments, for three successive seasons. Using pedigree-based QTL mapping software, FlexQTL ${ }^{\text {TM }}$, evidence was found for only two QTLs, on linkage groups 16 (the reported Ma locus) and LG 8 (here called Ma3) that jointly explained $66 \pm 5 \%$ of the phenotypic variation. An additive allele dosage model for the two QTLs effectively explained most acidity variation, with an average of $+1.8 \mathrm{mg} / \mathrm{L}$ at harvest per high-acidity allele. The more high-acidity alleles, the faster the depletion with storage, with all combinations appearing to eventually converge to a common baseline. All parent cultivars and selections had one or two of the four possible high-acidity alleles. Each QTL had a rare second high-acidity allele with stronger or reduced effect. Diagnostic SNP markers were identified for QTL alleles derived from distinct sources. Combined QTL effects highlighted utility of the DNAbased information in new cultivar development for targeting desired fruit acidity levels before or after storage.
\end{abstract}

Keywords FlexQTL ${ }^{\mathrm{TM}} \cdot$ Malic acid $\cdot$ Malus $\times$ domestica $\cdot$ Pedigree-Based Analysis $\cdot$ RosBREED

Communicated by D. Chagné

Electronic supplementary material The online version of this article (https://doi.org/10.1007/s11295-019-1324-y) contains supplementary material, which is available to authorized users.

\section{P. Peace}

cpeace@wsu.edu

1 Department of Horticulture, Washington State University, Pullman, WA 99164, USA

2 Present address: Department of Horticultural Science, IFAS Gulf Research and Education Center, University of Florida, Wimauma, FL 33598, USA

3 Tree Fruit Research and Extension Center, Department of Horticulture, Washington State University, Wenatchee, WA 98801, USA

4 Department of Horticultural Science, University of Minnesota, St. Paul, MN 55108, USA

5 Department of Horticulture, Michigan State University, East Lansing, MI 48824, USA
6 Present address: CIMMYT International, Global Wheat Program, CP 56237 Texcoco, Mexico

7 Present address: Institut für Biologie und Umweltwissenschaften, Carl von Ossietzky Universität, 26129 Oldenburg, Germany

8 National Clonal Germplasm Repository, Agricultural Research Service, United States Department of Agriculture, Corvallis, OR 97333, USA

9 Biometris, Wageningen UR, PO Box 16, 6700 AA Wageningen, The Netherlands

10 Present address: Research \& Technology Center, Hendrix Genetics, 5830 AC Boxmeer, The Netherlands

11 Plant Breeding, Wageningen UR, 6708 PB Wageningen, The Netherlands 


\section{Introduction}

Acidity is a critical component of the apple fruit consumption experience. Apple fruit are popular worldwide, consumed as either fresh or processed products and contributing to human health and well-being (Iwanami et al. 2012). Fruit acidity affects overall apple flavor and the perception of other flavor traits such as sweetness and aroma, therefore influencing consumer satisfaction (Harker et al. 2003; Iwanami et al. 2012). Malic acid is the major organic acid in mature apple fruit (Zhang et al. 2010), and can be measured sensorially by taste or instrumentally by titration or as organic acid content of fruit juice. Commercially, most apple fruit are stored then eaten months to a year after harvest because apples are harvested for only 3 to 4 months yet available to consumers all year round (Watkins 2017). During storage, malic acid content declines (Haynes 1925; Kouassi et al. 2009) and can reach low levels associated with lower satisfaction for some segments of consumers (Harker et al. 2008). However, there is genetic variation for acidity levels before and after storage among common cultivars (Rouchaud et al. 1985; Iwanami et al. 2008) and among germplasm in breeding programs (Ma et al. 2015b; Cliff et al. 2016). An understanding of the components of that genetic variation for fruit acidity would aid development of new apple cultivars that produce fruit with target levels of acidity.

Genetic studies of apple fruit acidity have revealed the presence of major genetic factors. Wellington (1924) described "sweet flavor" (essentially the absence of strong acidity) as a recessive character. By evaluating apple seedlings on a five-point sensory scale from sour to sweet, Crane and Lawrence (1934) ascribed homozygosity or heterozygosity to more than 20 apple cultivars and almost 600 seedlings. Nybom (1959) and Visser and Verhaegh (1978) using independent segregation ratio analysis and analysis of variances, respectively, confirmed the observation that low acidity behaves as a recessive phenotype although it is rarely observed among apple cultivars and selections. Dove and Murphy (1936) and Nybom (1959) suggested that early seedling selection for fruit acidity levels could be conducted using the indirect measure of leaf pH. Visser and Verhaegh (1978) introduced the Malic acid (Ma) locus to explain these observations of relatively simple inheritance.

Quantitative trait loci (QTLs) for apple fruit acidity have been located in the apple genome, especially at the $M a$ locus. Maliepaard et al. (1998) were the first to map the $M a$ locus as a morphological marker to the top of linkage group (LG) 16 using a biparental $F_{1}$ mapping family for which both parents were heterozygous. Using QTL interval mapping with common cultivars as parents, numerous studies reported incomplete dominance of the high-acidity " $M a$ " allele over the lowacid " $m a$ " allele (King et al. 2000, 2001; Liebhard et al. 2003; $\mathrm{Xu}$ et al. 2012; Khan et al. 2013). Liebhard et al. (2003) described a second significant QTL for acidity on LG 8 that explained $46 \%$ of the phenotypic variation in a cross between 'Fiesta' and 'Discovery' that also segregated for $M a(42 \%$ of the phenotypic variation). Similarly, Kenis et al. (2008) using the biparental family 'Telamon' $\times$ 'Braeburn' reported significant QTLs for acidity at both loci: in the vicinity of the $M a$ locus in two consecutive years as well as on LG 8, although the latter was detected in only one of the years. Zhang et al. (2012), using the biparental family 'Jonathan' $\times$ 'Golden Delicious,' reported a LG 8 QTL for malic acid that explained $13.5 \%$ of the phenotypic variation (total organic acid content assessed by gas chromatography). Ma et al. (2016) reported QTL at both loci that explained $12 \%$ and $14 \%$ of the phenotypic variation. Kumar et al. (2012) also reported QTLs for acidity on LG 8 and LG 16 in a genomic selection study with a training population of seven full-sib families. King et al. (2000), using the same mapping population as Maliepaard et al. (1998), reported a QTL for acidity in the vicinity of the $M a$ locus, with significant influences also on firmness and sensory traits of crispness, juiciness, sponginess, and overall liking. Minor QTLs for acidity were reported on LGs 2, 10, 13, 15, and 17 in the 'Telamon' $\times$ 'Braeburn' family (Kenis et al. 2008). In a cross between 'Royal Gala' and the Malus sieversii accession PI 613988, Xu et al. (2012) detected a major QTL at the $M a$ locus and minor QTLs for acidity on LGs 1 and 6.

Allelic variation in genes of the biochemical pathways underlying fruit acidity biosynthesis and degradation or in genes that affect the transport, storage, and use of acids might underlie the detected QTLs. Several biochemical pathways are involved in the synthesis and metabolism of malate, the precursor of malic acid. In the glycolysis pathway, carboxylation of phosphoenol pyruvate occurs in the cytoplasm, producing oxaloacetate, which is reduced to the volatile compound malate by NAD-dependent malate dehydrogenase (Etienne et al. 2013). Other pathways that could also influence cytoplasmic malate content are as follows: the conversion of malate from pyruvate by NADP-linked malic enzyme in the chloroplast; the conversion to malate of glyoxylate and oxaloacetic acid by malate synthase and NAD-linked malate dehydrogenase, respectively, in the glyoxysome; the conversion of malate from fumarate by fumarase in mitochondria; and the efflux of malate from the vacuole into the cytoplasm (Sweetman et al. 2009). Once fruit are harvested, continued respiration depletes available cellular malate, underlying the typical reduction in acidity throughout the postharvest storage period (Etienne et al. 2013). Bai et al. (2012) provided strong evidence that underlying the $M a$ locus is an aluminum-activated malate transporter gene (ALMT1) coding for the protein responsible for transporting malic acid molecules from the cytosol to the vacuole where $\sim 90 \%$ of cell sap is stored. The transport of malate over the vacuole is dependent on the acidity level of the vacuole and membrane potential across the tonoplast (Martinoia et al. 2007). More acidic conditions within the 
vacuole can lead to a change in the malate's protonation state, which can further support accumulation, especially if the transporter involved is specific for one form of malate (Martinoia et al. 2007). In plants, the proton pumps VATPase and V-PPase are involved in vacuolar acidification (Martinoia et al. 2007). In apple, such genes have been identified, and their involvement in vacuolar acidification and malate accumulation has been confirmed (Hu et al. 2016, 2017; Jia et al. 2018). Coordination of these proton pumps and malate transporters is under research and seems to involve a complex network of regulating and signaling genes that include the MYB genes MdMYB1, MdMYB44, and MdMYB73 (Hu et al. 2016, 2017; Jia et al. 2018) of which MdMYB73 is influenced by, among others, the MdCIbHLH1 gene involved in cold tolerance (Hu et al. 2017).

Knowledge gained from genetic dissection of apple acidity is not yet sufficient for widespread exploitation in breeding. For the most consistently detected trait loci on LG $16(\mathrm{Ma})$ and LG 8 (hereby termed Ma3), several unknowns remain. It is unclear whether the QTL effects are maintained across genomic backgrounds of typical breeding germplasm. The highor low-acidity alleles reported across the various families might be identical-by-descent or represent distinct sources that might differ in quantitative effects. How allelic combinations at the two loci interact to produce genetic potential for fruit acidity is unexplored. Other QTLs might also significantly contribute to acidity genetic potential in wider germplasm than that represented by the biparental family parents. Reports described influences of the loci on freshly harvested fruit, but the more commercially pertinent effects on fruit after storage are not known. Determining the frequency of acidityassociated alleles and their distributions across breeding germplasm would help determine the breeding relevance of significant loci.

Key experimental resources are now in place to characterize the major genetic factors influencing apple fruit acidity at harvest and after storage for diverse breeding germplasm. Genetic improvement in fruit quality via superior new scion cultivars that can satisfy both consumer and industry needs is a primary target of the multi-institutional, US-wide, and international RosBREED project (Iezzoni et al. 2010; www. rosbreed.org) and the participating Washington State University (WSU) Apple Breeding Program (Evans 2013). The pedigree-based analysis (PBA) approach (van de Weg et al. 2004; Bink et al. 2012, 2014) has been established for the aforementioned breeding program in the RosBREED project, enabling efficient detection and validation of segregating alleles in multiple families (Peace et al. 2014). The US apple Crop Reference Set (CR Set), representing alleles of important parents of US apple breeding germplasm, has been established (Peace et al. 2014) and phenotyped for numerous traits, including fruit quality after storage, using standardized protocols (Evans et al. 2012).
The objectives of this study were to determine the number and location of QTLs for acidity variation in a large apple breeding program and ascertain the quantitative effects and breeding relevance of QTL allelic combinations at harvest and after commercially relevant periods of cold storage.

\section{Materials and methods}

\section{Breeding germplasm}

The germplasm set used was a subset of the US apple Crop Reference Set supplemented with a Breeding Pedigree Set specific to the WSU program and chosen to efficiently represent genome-wide alleles of important breeding parents of the WSU breeding program as described by Peace et al. (2014). Parentage records were verified first using three SSR markers, Md-Exp7 ${ }_{\text {SSR }}$ (Costa et al. 2008), CH05c06, and Hi04e04 (Silfverberg-Dilworth et al. 2006; Velasco et al. 2010) and then with SNP array markers using procedures described in Pikunova et al. (2013) and van de Weg et al. (2018). The final pedigree-connected germplasm consisted of $16 F_{1}$ full-sib families with 200 offspring (Online Resource 1) representing nine important breeding parents ('Arlet,' 'Aurora Golden Gala,' 'Cripps Pink,' 'Delicious,' 'Enterprise,' 'Honeycrisp,' 'Splendour,' 'WA 5,' and selection W1), 25 of their ancestors, and 18 genetically related cultivars and selections supporting the phasing of marker data in ancestral generations.

\section{Phenotypic data}

Crop load management and fruit maturity assessment were conducted according to Evans et al. (2012). Titratable acidity (TA, in $\mathrm{mg} / \mathrm{L}$ malic acid equivalents) using an Auto-Titrator (Metrohm 815 Robotic USB Sample Processor XL, Metrohm USA, Inc., Riverview, FL, USA) was determined for fruit of the germplasm set over three harvest years with three storage treatments within each year: at harvest with no storage $(\mathrm{H})$; after 10 weeks of cold storage followed by 1 week at room temperature $(10 \mathrm{wk})$; and after 20 weeks of cold storage followed by 1 week at room temperature (20wk), as described by Evans et al. (2012). These storage periods were chosen for their commercial relevance. For each assessment, the juice of equally sized portions of preferably five but at least four fruit were pooled. Phenotypic data were checked for errors and statistical outliers by plotting phenotypic correlations among pairs of years within a storage treatment and plotting TA levels over storage within each year. To identify erroneous data within expected bounds for an individual but outside the overriding trend of decreasing TA levels over storage, triplets of data points over the three storage periods for each individual within each year were examined for TA increases of more than $1.5 \mathrm{mg} / \mathrm{L}$ from $\mathrm{H}$ to $10 \mathrm{wk}$ or from $10 \mathrm{wk}$ to $20 \mathrm{wk}$. Twenty- 
one such single deviating data points were removed (Online Resources 2 and 3). Inspection of each individual triplet identified one more individual with an unusually low acidity at 20wk in 2012, for which a data point was then made missing (Online Resource 4). To identify erroneous data across years, triplets across years for each individual at $\mathrm{H}$ were examined for cases of one data point being at least $2 \mathrm{mg} / \mathrm{L}$ higher or lower in TA than the other two data points, and were subsequently made missing (Online Resource 5). To avoid biases from prior breeding selection for superior performance (Peace et al. 2014), only the phenotypic data of offspring within the full-sib families were used for QTL analyses. The original phenotypic data set prior to the above-described curation is provided in Online Resource 6, together with the curated data set.

\section{Heritability}

A linear mixed model (individual or animal model) was fitted to the titratable acidity data using univariate analyses in ASReml software 4.1:

$y_{i j k l}=\mu+S_{i}+\operatorname{ind}_{j}+\operatorname{fam}_{k}+c(\text { fam })_{k l}+e_{i j k l}$

where $\mu$ is the overall mean; $S_{i}$ is a fixed year-replicate effect; ind $_{j}$ is the random additive effect of individual, with ind NID $\left(0, \sigma_{a}^{2} A\right)$ where $A$ is the matrix numerator relationship based on genome-wide inbreeding coefficients calculated from pedigree information and where $\operatorname{NID}\left(0, \sigma_{a}^{2}\right)$ means normally and independently distributed with mean 0 and variance $\sigma^{2}$; fam is the family random effect, with fam $\sim \mathrm{NID}\left(0, \sigma_{f}^{2}\right) ; c$ (fam) is the random effect of individuals within families, with $c \sim \operatorname{NID}\left(0, \sigma_{o}^{2}\right)$; and $e$ is the residual term, with $e \sim \operatorname{NID}\left(0, \sigma_{e}^{2}\right)$. Narrow-sense heritability $\left(h^{2}\right)$ and broad-sense heritability $\left(H^{2}\right)$ were calculated from the following expressions:

$$
\begin{aligned}
& h^{2}=\sigma_{a}^{2} / \sigma_{p}^{2} \\
& H^{2}=\left(\sigma_{a}^{2}+\sigma_{f}^{2}+\sigma_{o}^{2}\right) / \sigma_{p}^{2} \\
& D^{2}=4 \sigma_{f}^{2} / \sigma_{p}^{2 .} \\
& I^{2}=\left(\sigma_{o}^{2}-3 \sigma_{f}^{2}\right) / \sigma_{p}^{2}
\end{aligned}
$$

where $\sigma_{a}^{2}$ is the additive variance, $\sigma_{f}^{2}$ is the family variance, $\sigma_{o}^{2}$ is the variance component associated with individuals within family replicated over years, $\sigma_{e}^{2}$ is the total residual variance, and $D^{2}$ and $I^{2}$ are dominance and epistasis effects, respectively, expressed as proportions of total phenotypic variance (Costa e Silva et al. 2004). Total phenotypic variance was calculated from the observed phenotypic data and set equal to the above mentioned variance components as $\sigma_{p}^{2}=\sigma_{a}^{2}+\sigma_{f}^{2}+\sigma_{o}^{2}+\sigma_{e}^{2}$, and the residual variance was calculated as $\sigma_{e}^{2}=\sigma_{p}^{2}-\sigma_{a}^{2}-\sigma_{f}^{2}-\sigma_{o}^{2}$.

\section{Genotypic data}

Progenies and available progenitors were genotyped with the International RosBREED SNP Consortium apple 8K SNP array v1, an Infinium ${ }^{\mathrm{TM}}$ array (Chagné et al. 2012a). GenomeStudio ${ }^{\mathrm{TM}}$ genotyping software was used for marker calling. Next, ASSIsT software (Di Guardo et al. 2015) was used for filtering of SNP markers, whereby markers with recognized null alleles were removed, and to prepare an input file in FlexQTLTM format via software FlexQTL DataPrepper (www.flexqtl.nl). Marker data were curated using marker consistency, double recombination reports, graphical genotyping plots as generated by FlexQTL ${ }^{\mathrm{TM}}$ and VisualFlexQTL (Bink et al. 2014, www.flexqtl.nl), and problematic markers were eliminated and double-recombinant singletons were made missing through FlexQTL ${ }^{\mathrm{TM}}$ parameter settings. Genetic positions of the filtered 1344 SNP markers for QTL analysis were obtained from an early version of Howard et al. (2017), with an average position difference of $0.33 \mathrm{cM}$ and with any additonal SNPs (such as ss475879082, ss475882553, and ss475883359) genetically positioned by relative physical location. SNP data on ancestors that had not been genotyped within the RosBREED project were complemented where feasible with $20 \mathrm{~K}$ Infinium ${ }^{\mathrm{TM}}$ SNP array (Bianco et al. 2014) data from the FruitBreedomics project (Laurens et al. 2010, 2018) (data not shown). The reported causal SNP for the major phenotypic difference at the Ma locus, Ma1-SNP1455 (Bai et al. 2012) , was also used to genotype the germplasm set using Taqman ${ }^{\circledR}$ assay AHCTENE (Chagné et al. 2019); this SNP was used to confirm results from the QTL analyses. Positions of markers on the GDDH13v1.1 reference genome were determined from the Genome Database for Rosaceae (Jung et al. 2014) using BLASTn or, in cases of no hits, through manual examination of this genome sequence through the genome browser at https:// iris.angers.inra.fr/gddh13/ "visit the apple genome."

\section{QTL detection and characterization}

FlexQTL ${ }^{\mathrm{TM}}$ software, which implements pedigree-based QTL analysis via Markov Chain Monte Carlo (MCMC) simulation (Bink et al. 2002, 2014; www.flexqtl.nl), was used for QTL analyses, where an initial genome-wide analysis was followed by an analysis targeting only the set of LGs that harbored significant and repeatable QTLs. The model parameter settings (Online Resource 7) enabled convergence to be reached. The Bayes factor parameter $\left(2 \operatorname{lnBF}_{10}\right)$ was interpreted as nonsignificant (0-2), positive (2-5), strong (5-10), or decisive (> 10) evidence for presence of QTLs (Kass and Raftery 1995). Chromosome-wide evidence was collected for $N_{\mathrm{QTL}}$ models $1 / 0$ and $2 / 1$ to $n n-1$. QTLs were considered significant and repeatable where the $2 \operatorname{lnBF}_{10}$ for QTLs in the same genomic region for at least most of the nine evaluation points were equal to or greater than 5. For data of each storage period, replicated runs were performed until two runs were obtained 
that met the effective chain size criteria for convergence. QTL regions were recorded as a series of successive $2 \mathrm{cM}$ bins with $2 *$ In Bayes factors that were greater than 5. MapChart (Voorrips 2002) and VisualFlexQTL ${ }^{\mathrm{TM}}$ (www.flexqtl.nl) software were used to visualize FlexQTL ${ }^{\text {TM }}$ output on traces of convergence of QTL models, positions, and genotypes. The mode of a QTL was used as its most probable position. Delineation of QTL regions, QTL genotypes $(Q Q, Q q$, or $q q$ ), breeding values, and additive variances associated with the QTL regions were estimated with FlexQTL ${ }^{\mathrm{TM}}$, where alleles $Q$ and $q$ refer to alleles associated with high and low phenotypic values, respectively.

The QTL analyses of FlexQTL ${ }^{\mathrm{TM}}$ aggregates segregation information across SNPs. It translate this information to IBD probabilities of $2 \mathrm{cM}$ bins (chromosome segments), whereby founder alleles are used as statistical factors. This aggregation of segregation information makes the analyses less sensitive for individual markers having (some) missing data. To facilitate downstream analyses by other software, we imputed missing data for the QTL-associated SNP markers where possible. Original and missing-data-curated genotypic data are provided in Online Resource 6.

The proportion of phenotypic variance explained by each QTL was estimated from FlexQTL ${ }^{\mathrm{TM}}$ output of an additive genetic model by dividing the variance explained by the QTL region (AVt1) by the total phenotypic variance for each run replicate (similar to Mangandi et al. (2017) but in that paper the QTL variances were incorrectly weighted by the probability, the proportion of sampled QTL models that upheld the QTL; as the QTL reported there had a probability close to 1, the numerical difference is minimal). These estimates were conducted only where the QTL genotypes of full-sib family parents were identical to consensus QTL genotypes across all years and run replicates determined for the at-harvest data.

The SNPs chosen for haplotyping each QTL were those within a region representing a consensus of the highest posterior densities determined by FlexQTL ${ }^{\mathrm{TM}}$ for each storage period-year-run replicate QTL analysis. At the Ma3 QTL, three SNPs (ss475876134, ss475882878, and ss475879095) were removed that had a redundant segregation pattern across all germplasm to other SNPs (ss475882875, ss475878886, and ss475879097, respectively). Haplotypes were constructed across the germplasm for $M a$ and $M a 3$ using PediHaplotyper (Voorrips et al. 2016), including automated imputation of missing data, with marker phasing by FlexQTL ${ }^{\mathrm{TM}}$.

To examine differences in effect among $Q$ alleles of different origin, offspring were assigned to compound $\mathrm{Ma}$ and $\mathrm{Ma} 3$ QTL genotypes such that comparisons could be based on individuals with the same genotype for the second acidity QTL. Cumulative frequency distributions for TA content at harvest, using averages for each of the 3 years, were generated and year-pairs of distributions were statistically tested for differences with the two-sample Kolmogorov-Smirnov test $(p<0.05)$. Families derived from selection $\mathrm{W} 1$ were excluded from such quantitative analyses of $M a$ alleles because of functional diversity detected between its Ma3 alleles. To examine differences in effect among QTL alleles at Ma3 for W1, W1 offspring were categorized according to their SNP haplotype at Ma3. Each of the two sets was further subdivided into three classes according to their FlexQTL ${ }^{\mathrm{TM}}$-estimated number of "background" $q$ alleles at $M a$ and Ma3. Next, TA values were normalized by dividing an individual's observed TA by the average TA of the offspring with the same number of background $Q$ alleles. Effects of the two W1 haplotypes were then compared across each background using the two-sample Kolmogorov-Smirnov test $(p<0.05)$. Representation of marker haplotypes in the breeding families was calculated based on FlexQTL ${ }^{\text {TM}}$-derived identity-by-descent (IBD) estimates (reported in FlexQTL's output file "pedimap.ped").

Dominance levels of each QTL were calculated from the difference between TA content of $Q q$ heterozygotes and the mean of the $q q$ and $Q Q$ homozygotes, expressed as its proportion of half the difference in TA content between the two homozygotes. The level of dominance of each QTL was estimated for each storage period and year on subsets of offspring that had the same QTL genotype for the other, non-targeted QTL and that also had at least three individuals representing each of the three QTL genotype classes. In case of inconsistencies, the most prevalent genotype was used. These obtained consensus QTL genotypes were used in each of the nine storage period-year combinations.

\section{Results}

\section{Acidity changes over storage and stability over years}

In the original phenotypic data set, differences between years in TA at harvest were as high as $4.2 \mathrm{mg} / \mathrm{L}$ within the same individuals. After conversion of at-harvest data to missing for 22 offspring deviating by at least $2.0 \mathrm{mg} / \mathrm{L}$ for 1 year from the other two, higher correlations between years were achieved with $r^{2}$ increasing from $0.54-0.66$ to $0.65-0.78$ (Online Resource 8). After this phenotypic data curation, across all progenies and years, TA decreased by an average of $2.5 \mathrm{mg} /$ L over the entire storage and ripening period (Fig. 1). For most offspring, about half this acidity loss had occurred after the mid-duration storage treatment of 10wk (Fig. 1), such that for each year the three data points for the three storage periods were tight to their regression line (Online Resource 2). Within each family, TA distributions tended to be continuous at harvest, and the prevalence of discontinuous distributions increased with storage period (Online Resource 9).

Broad- and narrow-sense heritability estimates decreased with storage duration, from 0.87 and 0.84 respectively at harvest to 0.63 and 0.22 for $20 \mathrm{wk}$ (Table 1 ). The calculated 
Fig. 1 Boxplot distributions of titratable acidity measured for each of 3 years (2010-2012) at three storage durations $(\mathrm{H}=$ at harvest with no storage; $10 \mathrm{wk}=$ after 10 weeks of cold storage followed by 1 week at room temperature; $20 \mathrm{wk}=$ after 20 weeks of cold storage followed by 1 week at room temperature) on 243 apple germplasm individuals representing nine important breeding parents (listed in Table 2)

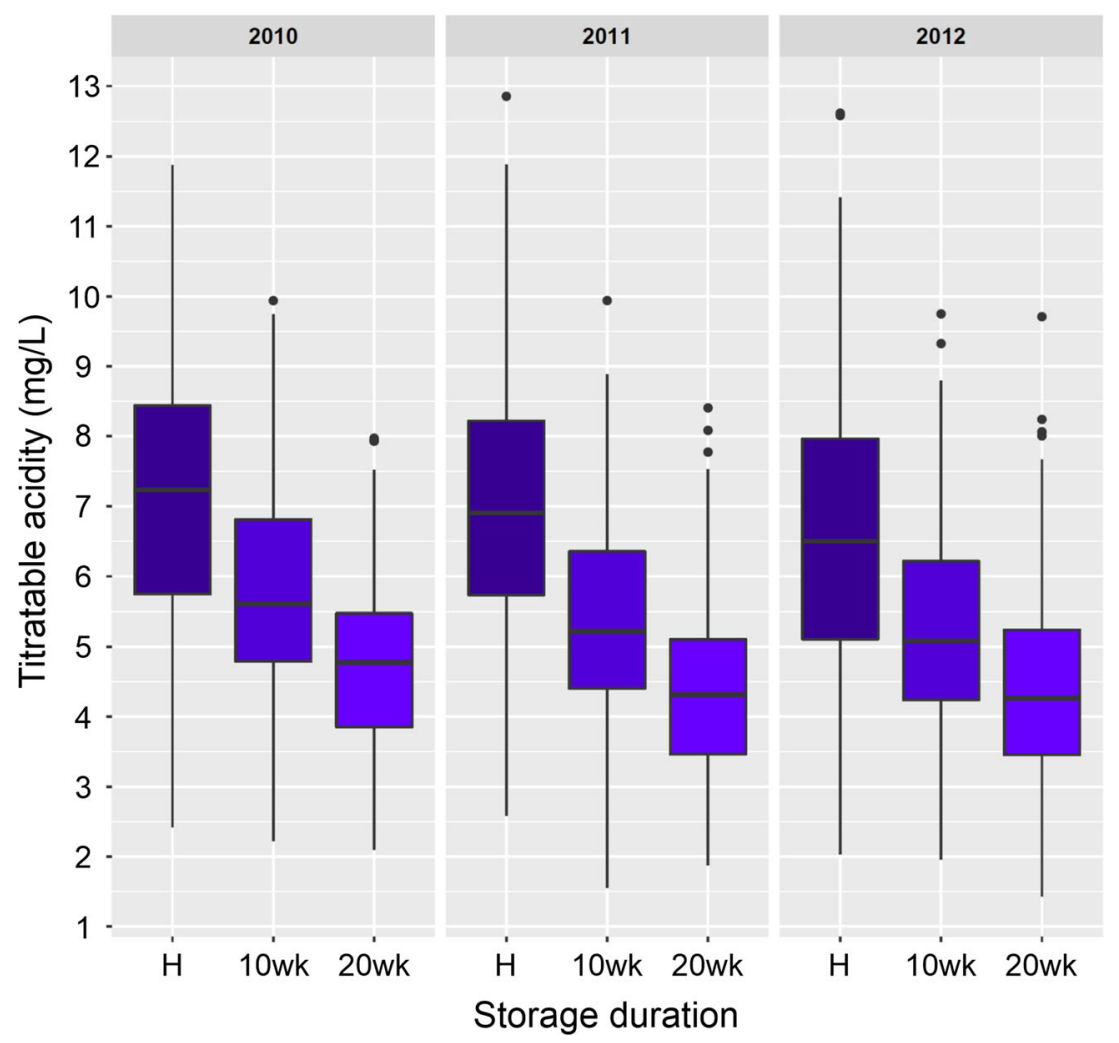

variance components of the broad-sense heritability associated with family and individuals within families were minor for $\mathrm{H}$ and 10wk, thus supporting use of an additive genetic model in QTL analyses. However, for 20wk, these two variance components and additive variance had similar contributions and each had large standard errors.

\section{QTLs detected: $M a$ and $M a 3$}

For each storage treatment and year combination, two to six simulations with different seeds were needed to obtain full convergence in two of those simulations that were then designated as two replicate runs. At harvest, two QTLs for fruit acidity with decisive statistical evidence $\left(2 \operatorname{lnBF}_{10}>30\right)$ were detected at LG 8 and LG 16 in each year and with each replicative run, and no further significant QTLs were found (Online Resource 10). Genetic positions of the mode of each of these two QTLs varied

Table 1 Heritability estimates for titratable acidity ( \pm standard errors) at three storage periods across 3 years. $H^{2}$ and $h^{2}$ are broad- and narrowsense heritability estimates, respectively, and $D^{2}$ and $I^{2}$ are family and individuals-within-family components of $H^{2}$, respectively

\begin{tabular}{llllr}
\hline & $H^{2}$ & $h^{2}$ & $D^{2}$ & \multicolumn{2}{l}{$I^{2}$} \\
\hline $\mathrm{H}$ & $0.87 \pm 0.02$ & $0.84 \pm 0.08$ & $0.05 \pm 0.10$ & $-0.01 \pm 0.14$ \\
10wk & $0.73 \pm 0.05$ & $0.61 \pm 0.18$ & $0.07 \pm 0.13$ & $0.04 \pm 0.19$ \\
$20 \mathrm{wk}$ & $0.63 \pm 0.05$ & $0.22 \pm 0.20$ & $0.22 \pm 0.23$ & $0.19 \pm 0.21$ \\
\hline
\end{tabular}

by approximately $5 \mathrm{cM}$ among years (Fig. 2) and were considered to represent the same QTL. The position mode of the LG 8 QTL was at $28 \mathrm{cM}$ for two of the years (2010 and 2012), and the frequency by which this position occurred in the sampled QTL models dominated that of any other position. In 2011, the QTL interval was more dispersed but included the consensus position. For the LG 16 QTL in 2010 and 2011, FlexQTL ${ }^{\text {TM }}$ results suggested it was positioned in the first $4 \mathrm{cM}$ of the chromosome, whereas for 2012 it tended to be detected in the $6-8 \mathrm{cM}$ bin. These LG 16 QTL positions coincided with the genetic position of the previously reported Ma (Maliepaard et al. 1998; Liebhard et al. 2003; Khan et al. 2013). Furthermore, two SNPs in the 6$8 \mathrm{cM}$ bin, ss475881682 and ss475876558, flanked the aluminum-activated malate transporter gene ALMT1 (MDP0000252114, Online Resource 11), previously determined to likely represent the gene underlying $M a$ (Bai et al. 2012; Khan et al. 2013; Ma et al. 2015b). Hereafter, the LG 16 QTL is considered to be $M a$. The LG 8 QTL is hereafter referred to as $\mathrm{Ma} 3$ ("Ma2" was previously assigned by Bai et al. (2012) to a candidate gene in the vicinity of $M a$ ).

QTL analyses for fruit acidity after storage detected QTLs at the same genomic regions as for at harvest, i.e., Ma and Ma3 (Fig. 2), and no additional significant QTLs were found (Online Resource 12). Evidence for the presence of these after-storage QTLs was more variable than for acidity at harvest although the posterior probability remained strong to decisive, except in one case (20wk in 2011) where the evidence was just below the threshold for both run replicates (Online Resource 12). 
a

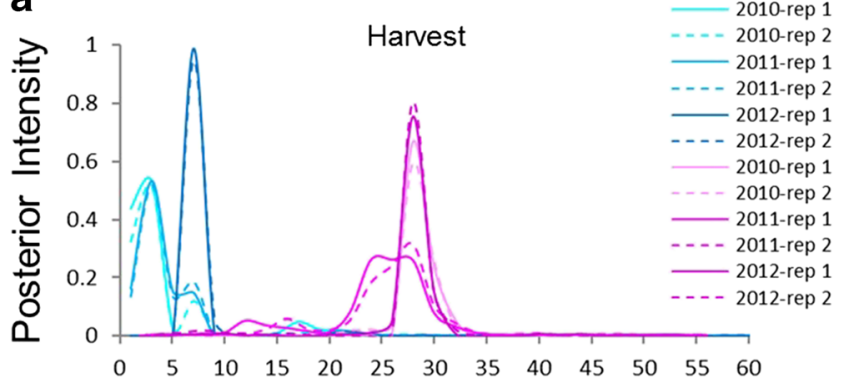

b
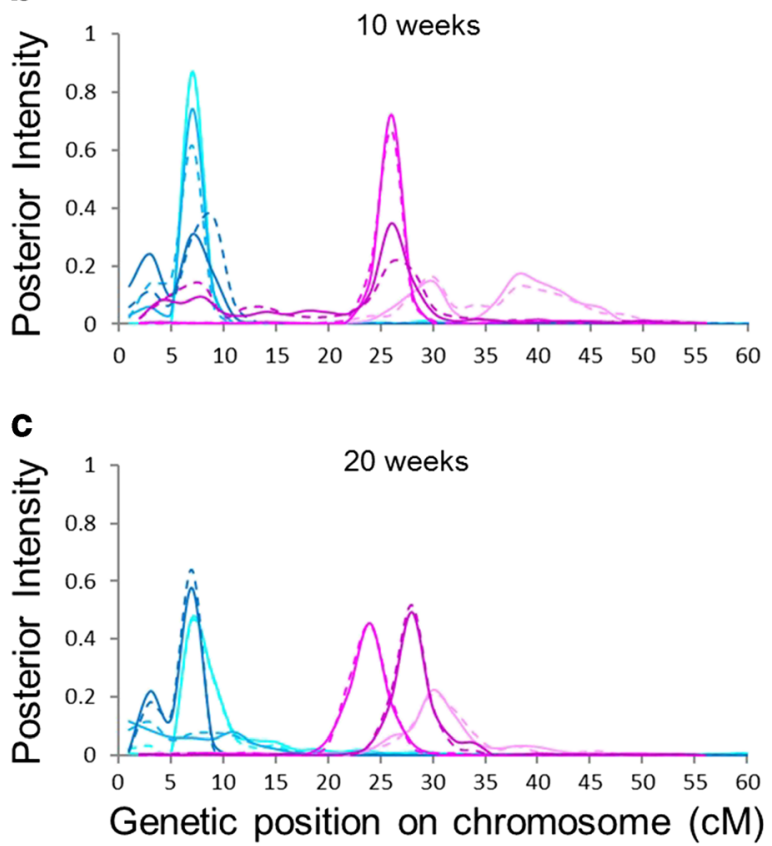

Fig. 2 Posterior intensities of acidity QTLs at Ma and Ma3 QTLs along their corresponding linkage groups (LGs) for three storage treatments. Panel $\mathbf{a}=\mathrm{H}$ treatment, at harvest. Panel $\mathbf{b}=10 \mathrm{wk}$ treatment (10 weeks of cold storage followed by 1 week at room temperature). Panel $\mathbf{c}=20 \mathrm{wk}$ treatment ( 20 weeks of cold storage followed by 1 week at room temperature). The $\mathrm{x}$-axis represents combined genetic locations of LG 16 (blue lines, $M a$ ) and LG 8 (pink lines, Ma3) in centimorgans (cM). The y-axis represents posterior intensities based on an additive genetic model executed by FlexQTL ${ }^{\mathrm{TM}}$ software. Increasing color grades correspond to successive years. Solid and dotted lines represent the two run replicates within each year's runs

\section{QTL genotypes of important breeding parents}

Genotype estimates revealed that the $Q$ allele representing relatively high-acidity levels was common among breeding parents for $M a$ and rare for $M a 3$ (Table 2). For $M a$, QTL genotypes for TA at harvest were mostly consistent across years and run replicates (Online Resource 13); two parents were classified as $Q Q$ ('Honeycrisp' and W1), while the other seven were classified as $Q q$. For Ma3, QTL genotype estimates for TA at harvest were also mostly consistent across years and run replicates; three were classified as $Q q$ ('Cripps Pink,' 'Enterprise,' and 'WA 5') and the other six were $q q$
Table 2 Summarized interpretation of $M a$ and $M a 3$ genotypes for important breeding parents. Full details for each of the two run replicates for each of three storage treatments and each of 3 years of phenotypic data are provided in Online Resource 13. Alternative $Q$ alleles $\left(Q_{2}\right)$ are described in the text

\begin{tabular}{lll}
\hline Important breeding parent & QTL genotype \\
\cline { 2 - 3 } & $M a$ & $M a 3$ \\
\hline Arlet & $Q q$ & $q q$ \\
Aurora Golden Gala & $Q q$ & $q q$ \\
Cripps Pink & $Q q$ & $Q q$ \\
Delicious & $Q q$ & $q q$ \\
Enterprise & $Q q$ & $Q q$ \\
Honeycrisp & $Q Q_{2}$ & $q q$ \\
Splendour & $Q q$ & $q q$ \\
WA 5 & $Q q$ & $Q q$ \\
W1 & $Q Q$ & $Q_{2} q$ \\
\hline
\end{tabular}

(Online Resource 13). $M a$ and Ma3 genotype estimates for 'Enterprise' and W1 were sometimes inconclusive at 10wk or 20wk. Consistent after-storage QTL genotype estimates for those two parents could not be identified from alternative parameter settings nor additional data curation considerations. The final interpretation of QTL genotypes for each of the nine parents (Table 2) was that determined from the at-harvest results. Although zero to four $Q$ alleles were possible within any individual across the two loci, all parent cultivars and selections had only one ('Delicious,' 'Arlet,' 'Aurora Golden Gala,' and 'Splendour') or two (all others) $Q$ alleles.

\section{Sources, associated SNPs, and effects of QTL alleles}

Ancestral origins of the parental $Q$ and $q$ alleles were successfully traced via SNP haplotypes spanning the QTLs (Table 3). For $M a$, each parent of the full-sib families had one or two $Q$ alleles that were traced through the pedigree to eight or nine ancestors: 'Winesap' 'Frostbite,' 'Duchess of Oldenburg,' NJ 27, NJ 136055, perhaps F2-26829-2-2, and the unknown paternal parents of 'Golden Delicious,' 'Jonathan,' and 'Lady Williams.' Ancestors 'Grimes Golden,' 'McIntosh,' and an unknown parent of 'Delicious' were the sources of $q$ alleles for the $M a$ QTL. For Ma3, the $Q$ alleles for high acidity in important breeding parents 'Cripps Pink,' 'Enterprise,' and 'WA 5' were inherited from ancestors 'Granny Smith,' 'McIntosh,' and F2-26829-2-2, respectively.

Specific SNP markers were indicative of the high-acidity $M a$ allele. The $B$-allele of SNP marker ss 475882553 was almost always associated with $Q-M a$ among the parental haplotypes. Only one $Q$-allele source ('Duchess of Oldenburg') lacked this SNP allele, but a unique $B$-allele at another SNP (ss475881815) was source-specific for this $Q$ allele. The presence of two distinct $Q$-allele sources for $M a$ was thus 
Table 3 QTL genotypes of Ma and Ma3 for nine important breeding parents, with associated SNP haplotypes and ancestral origins. QTL alleles are presented in order of maternal (top) and paternal (bottom) origin for each parent cultivar. SNP order for sequence of alleles follows the genetic map order provided in Online Resource 11 . The $B$-alleles of the second and fifth SNPs of $M a$, ss 475881815 and ss475882553, respectively, always associated with $Q$ alleles, are shown in bold. Ultimate ancestral sources are shown in bold italics at the end of the list of successive ancestors through which the IBD alleles could be traced, although those in parentheses were not included in the pedigree input data for QTL discovery. Evidences for the alternative $Q_{2}$ alleles are described in the text. Haplotypes with the same SNP allele sequence are given the same letter label; where such haplotypes traced to different founders, subscripts indicate the founder source, and those with different $Q / q$ effect designations are indicated by their suffix. At Ma3, the $B$ haplotype of Honeycrisp was determined to be derived from a recombination between founder haplotypes (E-ma3 of Grimes Golden and a unique haplotype of unknown effect from Duchess of Oldenburg)

\begin{tabular}{|c|c|c|c|c|c|}
\hline \multirow[t]{2}{*}{ QTL } & \multirow{2}{*}{$\begin{array}{l}\text { Important breeding } \\
\text { parent }\end{array}$} & \multirow[t]{2}{*}{ QTL allele } & \multicolumn{2}{|l|}{ SNP haplotype } & \multirow[t]{2}{*}{ Successive ancestors } \\
\hline & & & Allele sequence & Label & \\
\hline \multirow[t]{18}{*}{$M a$} & Honeycrisp & $Q_{2}$ & ABBAABBBAAA & $A-M a$ & MN $1627>$ Duchess of Oldenburg \\
\hline & Arlet & $Q$ & BAAABBAAABA & $B_{F 2 / J t}-M a$ & Idared $>$ (Jonathan, $\boldsymbol{F}$ _Jonathan $)$ \\
\hline & Enterprise & $Q$ & BAAABBAAABA & & $\begin{array}{l}\text { Co-op } 7>(\text { PRI 1018-9 }>\text { PRI 47-147 > F2-26829-2-2 or } \\
\text { Jonathan }>\text { F_Jonathan })\end{array}$ \\
\hline & Aurora Golden Gala & $Q$ & BAAАВBAAАВA & $B_{W s^{-}}-M a$ & Splendour $>$ Delicious $>($ Winesap $)$ \\
\hline & Delicious & $Q$ & BAAABBAAABA & & (Winesap) \\
\hline & Splendour & $Q$ & BAAABBAAABA & & Delicious $>$ (Winesap $)$ \\
\hline & Cripps Pink & $Q$ & BABBBABAABA & $C-M a$ & Lady Williams $>\left(\boldsymbol{F}_{-}\right.$Lady Williams $)$ \\
\hline & Honeycrisp & $Q$ & AABBBBBBBBB & $D-M a$ & Keepsake $>$ Frostbite \\
\hline & WA 5 & $Q$ & BAAABABAABA & $E-M a$ & Co-op $15>$ NJ 27 \\
\hline & W1 & $Q$ & AABABBAAABA & $F-M a$ & NJ $90>(N J 136055)$ \\
\hline & W1 & $Q$ & AABABBBAABA & $G-M a$ & Goldrush $>$ Golden Delicious $>($ Grimes Golden $)$ \\
\hline & Arlet & $q$ & AABAABBBBAB & $H-m a$ & Golden Delicious $>\left(\boldsymbol{F} \_\right.$Golden Delicious $)$ \\
\hline & Cripps Pink & $q$ & AABAABBBBAB & & Golden Delicious $>\left(\boldsymbol{F}_{-}\right.$Golden Delicious $)$ \\
\hline & Splendour & $q$ & AABAABBBBAB & & Golden Delicious > $\left(\boldsymbol{F} \_\right.$Golden Delicious $)$ \\
\hline & WA 5 & $q$ & AABAABBBBAB & & Splendour $>$ Golden Delicious $>($ Grimes Golden $)$ \\
\hline & Aurora Golden Gala & $q$ & BAAАABВВВАВ & I-ma & Gala $>$ Kidd's Orange Red $>$ Delicious $>\left(\boldsymbol{F}_{-}\right.$Delicious $)$ \\
\hline & Delicious & $q$ & BAAAABBBBAB & & $\left(\boldsymbol{F} \_\right.$Delicious $)$ \\
\hline & Enterprise & $q$ & BAAAABBBAAA & $J-m a$ & PRI1661-2 > McIntosh \\
\hline \multirow[t]{18}{*}{$M a 3$} & Cripps Pink & $Q$ & BAAABAAAA & $A-M a 3$ & Lady Williams > Granny Smith \\
\hline & Enterprise & $Q$ & BABBABBBA & $B_{M c}-M a 3$ & PRI1661-2 > McIntosh hap 1 \\
\hline & WA 5 & $Q$ & BAAABAAAB & $C_{F 2}-M a 3$ & Co-op $15>$ PRI 612-1 > (PRI14-126 > F2-26829-2-2) \\
\hline & W1 & $Q_{2}$ & ABBABBABB & $D-M a 3$ & NJ $90>$ Spartan > McIntosh hap 2 \\
\hline & Arlet & $q$ & BABBABBBB & $E-m a 3$ & Golden Delicious $>$ (Grimes Golden $)$ \\
\hline & Honeycrisp & $q$ & BABBABBBA & $\begin{array}{l}B_{G G+} \\
\quad D^{-}-m a 3\end{array}$ & $\begin{array}{l}\text { MN } 1627>\text { Golden Delicious/Duchess of Oldenburg > } \\
\quad \text { (Grimes Golden/Duchess of Oldenburg) }\end{array}$ \\
\hline & Aurora Golden Gala & $q$ & BAAABBABB & $F-m a 3$ & Splendour $>$ Golden Delicious $>(\boldsymbol{F}$ _Golden Delicious $)$ \\
\hline & Cripps Pink & $q$ & BAAABBABB & & Golden Delicious $>\left(\boldsymbol{F}_{-}\right.$Golden Delicious $)$ \\
\hline & Splendour & $q$ & BAAABBABB & & Golden Delicious > $\left(\boldsymbol{F} \_\right.$Golden Delicious $)$ \\
\hline & WA 5 & $q$ & BAAABBABB & & Splendour $>$ Golden Delicious $>($ F_Golden Delicious $)$ \\
\hline & W1 & $q$ & BAAABBABB & & Goldrush $>$ Golden Delicious $>\left(\boldsymbol{F}_{-}\right.$Golden Delicious $)$ \\
\hline & Arlet & $q$ & BAAABAAAB & $C_{E S}-m a 3$ & Idared $>$ Jonathan $>($ Esopus Spitzenburg $)$ \\
\hline & Aurora Golden Gala & $q$ & ABBABAABA & G-ma3 & Gala $>$ Kidd's Orange Red $>$ Delicious $>\left(\boldsymbol{F}_{-}\right.$Delicious $)$ \\
\hline & Delicious & $q$ & ABBABAABA & & (F_Delicious) \\
\hline & Splendour & $q$ & ABBABAABA & & Delicious $>\left(\boldsymbol{F} \_\right.$Delicious $)$ \\
\hline & Delicious & $q$ & BAAABAABB & $H-m a 3$ & (Winesap) \\
\hline & Enterprise & $q$ & ABBABAAAB & I-ma3 & Co-op $7>$ (PRI 1018-9 > PRI 47-147 > Jonathan > F_Jonathan $)$ \\
\hline & Honeycrisp & $q$ & AАВBBBBBB & $J-m a 3$ & Keepsake > Northern Spy \\
\hline
\end{tabular}

indicated, a common one characterized by ss475882553- $B$ $(Q)$ and a rare one by ss $475881815-B\left(Q_{2}\right)$. The $B$-alleles for those two SNPs were therefore always associated with a $Q$ allele of Ma. For the reported causal SNP of the Ma locus, 
Ma1-SNP1455 via the Taqman ${ }^{\circledR}$ assay AHCTENE, the $G$ allele was always associated with $M a$, both $Q$ and $Q_{2}$, and correspondingly the $A$ allele was always associated with $q$-ma.

Some cultivars shared the same SNP haplotype for $\mathrm{Ma} 3$ while these haplotypes came from different lineages and were associated with different-effect QTL alleles (Table 3). Haplotypes $B_{M c^{-}}$ $M a 3$ of 'Enterprise' and $B_{G G+D O}-m a 3$ of 'Honeycrisp' were identical-by-state (IBS) but not IBD according to available pedigree information, as 'Enterprise' inherited its haplotype from 'McIntosh' while that of 'Honeycrisp' appeared to have arisen from a recombination event in its paternal parent MN 1627 (data not shown). The other case was haplotype $C_{F 2}-M a 3$ of 'WA 5' (source: F2-26829-2-2) and haplotype $C_{E S}-m a 3$ of 'Arlet' (source: 'Esopus Spitzenburg'). In this case, recent recombination within the haploblock appeared unlikely because haplotypesharing extended for $36 \mathrm{cM}$ around this region (Online Resource 14). Lack of discrimination by the SNPs in the region also appeared unlikely because the phenomenon remained when using a higher resolution of 58 SNP markers from the 20K Infinium array (Bianco et al. 2014) within the same interval (data not shown). A comparison of harmonized TA data from subsets of offspring that had otherwise identical QTL genotypes (while distinguishing between $Q$ and $Q_{2}$ at both loci, results not shown) confirmed the statistical significance of the $Q / q$ contrast for the $C_{F 2}-M a 3$ and $C_{G G+D O}-m a 3$ haplotypes $(p=0.048)$.

The average effect of each $Q$-dose for each QTL across the 3 years was $+1.8 \mathrm{mg} / \mathrm{L}(\mathrm{H}),+1.2 \mathrm{mg} / \mathrm{L}(10 \mathrm{wk})$, and $+0.9 \mathrm{mg} /$ $\mathrm{L}(20 \mathrm{wk})$. Loss of acidity over storage was greater for genotypes associated with higher acidity at harvest (i.e., acidity loss $4 \times Q>3 \times Q>2 \times Q>1 \times Q>0 Q$ ). Extrapolated linear regression lines indicated that, with a hypothetical storage treatment of " $40 \mathrm{wk}$ " (40 weeks cold storage and 1 week at room temperature), fruit acidity levels converged to a common baseline level that depended on the year (Fig. 3). Loss of acidity over storage was greatest in 2011 for all genotypes, and this year had the lowest extrapolated baseline (Fig. 3c). Averaged over the three observed years, the extrapolated baseline was approximately $1.0 \mathrm{mg} / \mathrm{L}$ (Fig. 3d).

To determine whether the two $M a-Q$-allele types, common $Q$ and 'Duchess of Oldenburg'-derived " $Q_{2}$," were associated with consistently significant differences in effect size, comparisons were made among offspring that had these different $Q$-allele sources but the same genetic background at Ma3. These comparisons were among $\mathrm{Ma}-Q q, \mathrm{Ma}-Q_{2} q$, and $\mathrm{Ma}$ $q q$, with Ma3 always being homozygous $q q$. A statistically significant difference in TA content was observed $(p<0.005)$, whereby the rare 'Duchess of Oldenburg' $Q_{2}$ allele was associated with a higher TA content, $+0.5 \mathrm{mg} / \mathrm{L}$ at harvest across 3 years, compared to the common, multiancestor $Q$ allele (Fig. 4).

Evidence was obtained for the presence in the selection W1 of a $M a 3$ allele of higher acidity $\left(Q_{2}\right)$ with an effect in between that of the common $q$ and $Q$ alleles. Two families had W1
$\left(Q Q / q q\right.$ or $\left.Q Q / Q_{2} q\right)$ as a parent: 'Cripps Pink' $(Q q / Q q) \times$ W1 and W1 × 'WA 5' $(Q q / Q q)$. W1 segregated for its Ma3 $q$ alleles, $D-M a 3$ and $F$-ma3, which were respectively inherited without recombination by 13 and 29 offspring. Each of the two sets was further subdivided into three classes according to their number of $M a-Q$ and $M a 3-Q$ alleles. The set of offspring having the $D-M a 3$ allele had a higher average TA content at $\mathrm{H}$ and $10 \mathrm{wk}$ with each number of "background" $Q$ alleles and in each year (Online Resource 15). The distributions of the normalized TA values were statistically significantly different at $\mathrm{H}$ and $10 \mathrm{wk}$ for each year $(0.003<$ $p<0.047)$, except for $\mathrm{H}$ in $2011(p=0.38)$. The effect averaged $+0.8 \mathrm{mg} / \mathrm{L}$ (Online Resource 15), which was less than the effects of $+1.8 \mathrm{mg} / \mathrm{L}(\mathrm{H})$ and $+1.2 \mathrm{mg} / \mathrm{L}(10 \mathrm{wk})$ for the common Ma3-allele. Hence, W1 appeared to segregate for a $Q_{2}$ allele with an intermediate effect between $q$ and $Q$.

\section{Combined QTL effects}

Phenotypic variance explained by $M a, M a 3$, and $M a+M a 3$ was $26.9 \pm 2.4 \%, 39.1 \pm 0.6 \%$, and $66.0 \pm 1.9 \%$, respectively, across the six storage-year-replication combinations for which the estimated parental QTL genotypes were consistent with the consensus genotypes (Online Resources 13 and 16). The explained variance decreased with increasing storage duration for $M a$ (from $30.2 \pm 2.1$ for $\mathrm{H}$ to $20.5 \pm 0.3 \%$ for $10 \mathrm{wk}$ ) and remained stable for $\mathrm{Ma} 3(38.3 \pm 0.3 \%$ for $\mathrm{H}$ and $40.7 \pm 0.5 \%$ for 10wk). Estimated dominance levels of $M a$ and $M a 3$ for TA content across all years, run replications, and QTL genotypes were $5.8 \pm 1.1 \%$ and $1.5 \pm 1.9 \%$ respectively.

Considering both QTLs at once, fruit acidity increased with $Q$-allele dose at each storage period (Fig. 3). A single $Q$-dose at $M a$ was associated with a higher TA content than was a single $Q$-dose at $M a 3$, adding 2.0 and $0.7 \mathrm{mg} / \mathrm{L}$, respectively, at harvest (across all 3 years) compared to $q q$ genotypes. In the presence of a total of two $Q$ alleles across both loci, offspring heterozygous at both loci had slightly higher or equal (but never lower) TA content than offspring having both $Q$ alleles at $M a$ (Fig. 3). Comparisons to offspring with both $Q$ alleles at Ma3 could not be made as such germplasm was not present in the dataset. In the presence of a total of three $Q$ alleles, offspring homozygous at $M a 3$ tended to have a higher TA content than those homozygous at $M a$. The effect of both loci being $Q Q$-homozygous could not be estimated due to too few such offspring.

\section{Discussion}

Two large-effect QTLs influencing apple fruit acidity levels before and after commercially relevant fruit storage treatment were detected in US breeding germplasm. These QTLs were characterized across breeding families derived from nine parents with common ancestors but also distinct founders. The two QTLs 

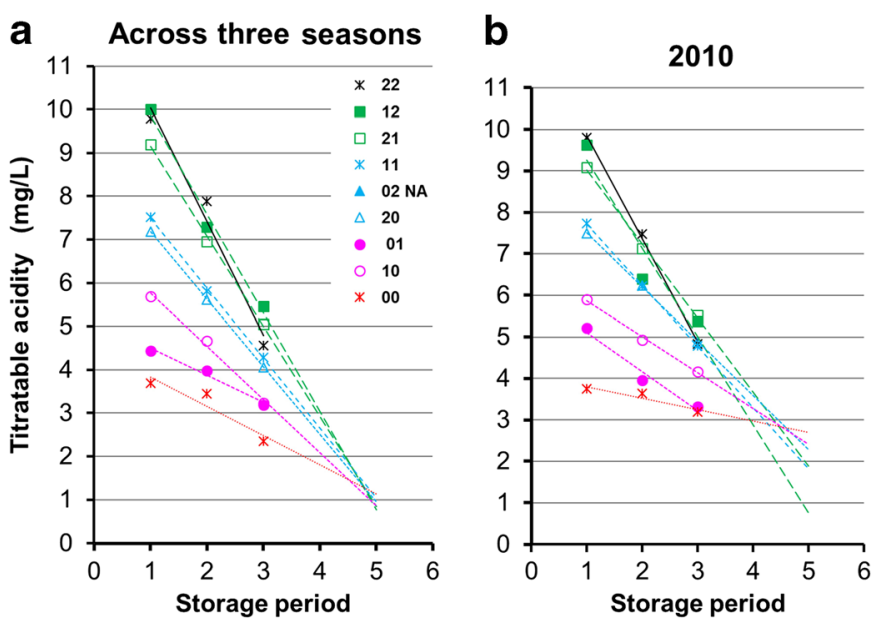

Fig. 3 Average fruit acidity content of $M a-M a 3$ compound genotypes over three storage periods observed for all three fruiting seasons (years) together (a) and each year individually (b-d). Regression lines are extrapolated beyond the experimentally observed storage periods. Compound genotypes are specified by two digits indicating the number of $Q$ alleles for $M a$ and $M a 3$ respectively. For example, " 12 " indicates the

that were consistently detected, Ma on LG 16 and Ma3 on LG 8 (the latter locus being newly named here), represented loci detected previously in biparental family studies. Combined effects of alleles from the two loci highlighted the utility of this DNAbased information in new cultivar development for targeting desired fruit acidity levels before or after storage.

\section{General genetic influences on fruit acidity from harvest through storage}

The high heritability estimates for apple fruit acidity at harvest $\left(H^{2}=0.87 \pm 0.02\right)$ and for the $10 \mathrm{wk}$ treatment $\left(H^{2}=0.73 \pm\right.$ $0.05)$, largely due to additive variance, across the 16 full-sib families from nine parents and 3 years of evaluation was as expected from previous studies (Baojiang et al. 1995; Maliepaard et al. 1998; Liebhard et al. 2003; Kouassi et al. 2009). These high estimates signified a large opportunity to identify the underlying genetic factors segregating in this germplasm. While it is difficult to harvest apple fruit in a
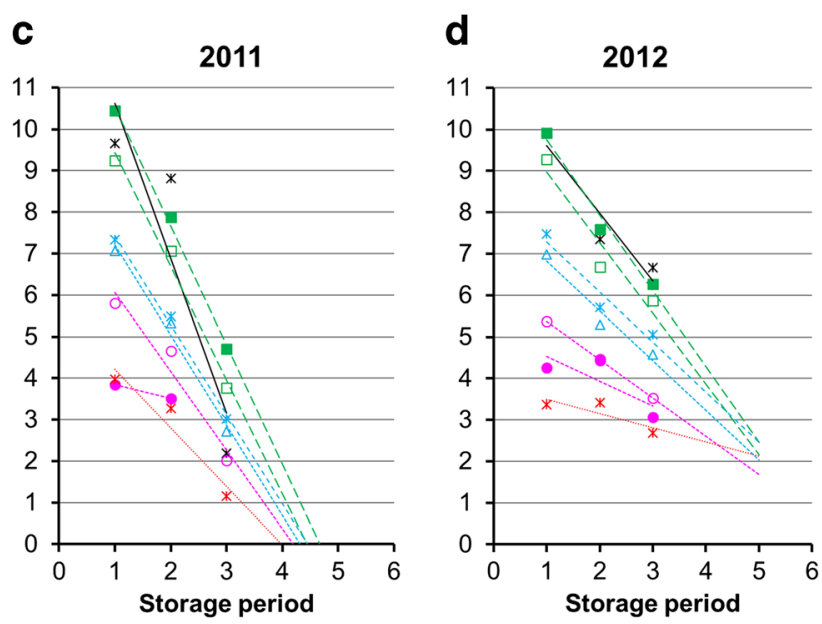

presence of one and two doses of the $Q$ allele for $M a$ and $M a 3$ respectively. QTL genotypes of offspring estimated with FlexQTL ${ }^{\text {TM }}$ were assigned from the at-harvest results and not considering the subsequently determined $Q_{2}$ alleles (thus, 'Honeycrisp' $=Q Q$ for $M a$ and $\mathrm{W} 1=q q$ for Ma3 here)

standardized manner from genetically variable populations (Evans et al. 2012; Howard et al. 2018), the high heritability estimates obtained indicate that any discrepancies in determining standardized maturity across trees within and among years were minimal for fruit acidity compared to genetic influences. Kouassi et al. (2009) reported narrow-sense heritabilities for four storage treatments of $0.79 \pm 0.01$ to $0.81 \pm 0.01$ for TA on 2207 pedigreed individuals in 29 families from breeding programs of six European countries. Those heritability estimates were therefore stable over storage and were also the highest among numerous fruit quality traits evaluated in that study, in contrast with our study's decrease in this general genetic signal with storage. The difference between our results and those of the previously mentioned report might be due to differences in phenotyping or statistical methods or storage treatments. More likely, there is a fundamental difference in QTL genotypes and alleles present - for example, several ancestors of Kouassi et al. (2009) were associated with extreme breeding values for acidity—-perhaps homozygous $Q Q$ for $M a 3$ and
Fig. 4 Cumulative frequency distribution of TA content at harvest for offspring differing for the source of their single $Q$ allele at $M a$ while having the same genotype ( $q q)$ at $M a 3$

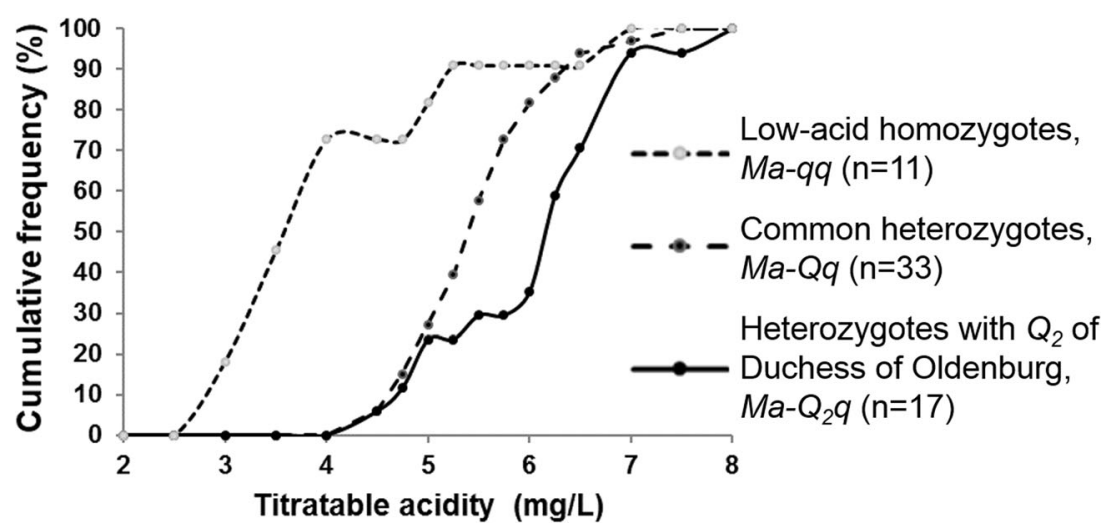


$M a$, or having " $Q_{3}$ " alleles associated with extremely high acidity - and germplasm of these types were not represented in the present study. The low additive genetic variance calculated for the $20 \mathrm{wk}$ treatment (Table 1) indicated limitations for an additive genetic model to adequately describe the phenotypic data. Reanalyzing the $20 \mathrm{wk}$ dataset with a genetic model in FlexQTL ${ }^{\mathrm{TM}}$ that allowed for the presence of both additive and dominance effects did not find dominance to be a significant effect for $M a$ and $M a 3$ (results not shown). The difference between the univariate analysis results, which indicated significant dominance effects for $20 \mathrm{wk}$, and the FlexQTL ${ }^{\mathrm{TM}}$ evidence showing otherwise might be due to dominance effects contributed by many small-effect trait loci other than $M a$ and Ma3 and thus were not detected by FlexQTLTM.

\section{Identities and effects of detected QTLs}

The two detected QTLs influencing apple fruit acidity for all storage treatments were the only ones that had statistical evidence. The detection of these two QTLs was consistent with previous reports on biparental families using fruit evaluated only at harvest. Our detected " $M a$ " locus was very likely that controlled by the aluminum-activated malate transporter ALMT1 gene on LG 16 described by Bai et al. (2012) and Khan et al. (2013), as evidenced by genomic positioning. Our "Ma3" might be identical to the acidity QTL reported on LG 8 by Liebhard et al. (2003), Kenis et al. (2008), Zhang et al. (2012), and Ma et al. (2015b) based on colocalization on aligned genetic linkage maps and/or the GDDH13 reference genome sequence (Online Resource 17).

Effects of the two QTLs detected were maintained across many genomic backgrounds typical of breeding germplasm, providing confidence in breeding consideration of genotypes for these QTLs. Our 9-parent, 16-family germplasm set had a wider range of genetic backgrounds than the biparental families of Liebhard et al. (2003), Zhang et al. (2012), and Ma et al. (2016) ('Fiesta' $\times$ 'Discovery,' 'Jonathan' $\times$ 'Golden Delicious,' and 'Jiguan' $\times$ 'Wangshanhong,' respectively), allowing for more allelic combinations of the two largeeffect QTLs and other influencing loci. Our large and similar effects calculated for the $M a$ and Ma3 QTLs were in agreement with those previous biparental studies. The phenotypic variance explained for each $(M a, 27 \pm 2 \%$ and $M a 3,39 \pm 1 \%$, with a combined effect of $66 \pm 2 \%$ ) was slightly less than Liebhard et al. (2003) reported ( $42 \%$ and $46 \%$, respectively), higher than reported by Ma et al. (2016) (12\% and 14\%, respectively) and Zhang et al. (2012) (13.5\% for Ma3) for their single Ma3. It is noteworthy that QTL effects were calculated to be so high in the present study, indicating that the two QTLs indeed account for the bulk of genetic variation for fruit acidity across a wide range of breeding germplasm. Kenis et al. (2008), using another biparental family ('Telamon' $x$ 'Braeburn'), reported 30-34\% of the phenotypic variation being explained by a LG 16 QTL $(M a)$, similar to above, but only $8 \%$ by a LG 8 QTL (Ma3). That lower influence of $M a 3$ can be now explained by the segregation of a $Q_{2}$ allele associated with acidity levels not as high as the common $Q$ allele.

$M a$ is reported to have additive gene action in papers where titratable acidity was used as the measure of fruit acidity (Liebhard et al. 2003), and dominant gene action was reported where $\mathrm{pH}$ was used (Maliepaard et al. 1998; Xu et al. 2012; Khan et al. 2013). These conclusions appear to be conflicting, but might be explained by differences in the scales of observation, TA being linear and $\mathrm{pH}$ being logarithmic. In QTL discovery approaches that assume additive gene action, such as in our current analysis, the use of TA would therefore be the appropriate measure of acidity. The appropriate QTL analytical model for sensory evaluations of acidity would depend on whether the scale was more aligned with $\mathrm{TA}$ or $\mathrm{pH}$. In the study of Jia et al. (2018) where malic acid content was assessed by HPLC, genetic action of the $M a$ allele varied between full-sib families, being dominant in 'Jonathan' $\times$ 'Golden Delicious' and additive in Malus asiatica 'Zisai Pearl' $\times M$. domestica 'Red Fuji.' The cause for this variable genetic action is not clear.

\section{Two-allele model and beyond}

In QTL modeling, FlexQTL ${ }^{\mathrm{TM}}$ assumes the presence of just two functional QTL alleles ( $Q$ and $q$ ), associated with high and low phenotypic values respectively. These associations are based on phenotypic contrasts among $Q$ and $q$ alleles determined to be different from IBD analysis across the pedigree structure. Observations of extended shared haplotypes across and around the QTL interval and other chromosomal regions (results not shown) indicate a recent shared, still unknown, ancestor, such as for $B_{F 2 / J t}-M a$ from F2-26829-2-2 or the unknown father of 'Jonathan' and $B_{W s}-M a$ from 'Winesap' (Table 3). However, as QTL alleles calculated to be functionally equivalent arose from numerous ancestral sources (founders) (Table 3), some of these sources might actually have a different QTL allele. Indeed, two extended shared haplotypes at $\mathrm{Ma} 3$ and beyond $\left(\mathrm{C}_{\mathrm{F} 2}-\mathrm{Ma} 3\right.$ and $C_{E S}-m a 3$, Online Resource 14) had contrasting $Q / q$ designations. As the contrasting $Q / q$ designations were confirmed by comparing offspring with otherwise identical QTL genotypes ( $p=0.01$ ), a mutation from $Q$ to $q$ or vice versa is likely to have occurred and might be of relatively recent origin. In cases such as both $C_{F 2}-M a 3$ and $C_{E S}-m a 3$ segregating, diagnostic DNA tests will need to ascertain lineage-specific effects or IBD estimates prior to use in marker-assisted selection.

It appears likely that each of the two QTLs have more than two-allele types, as represented by the $Q_{2}$ alleles. The higherthan-high-acidity $\mathrm{Ma}-Q_{2}$ allele of 'Honeycrisp,' inherited from 'Duchess of Oldenburg,' had a distinctive SNP haplotype including a unique allele for the second SNP. The reported causal SNP for the Ma locus, Ma1-SNP1455 (Bai et al. 2012; Chagné et al. 2019) was not able to distinguish the $M a-Q_{2}$ from $M a-Q$. 
However, a combination of any two of the three SNPs of Ma1SNP1455, ss 475881815 , and ss 475882553 would be effective to do so (and to establish a germplasm individual's $Q$-allele dosage). 'Duchess of Oldenburg' is an old Russian cultivar with origins distinct from the bulk of European and US apple germplasm (Beach et al. 1905), so the unique effect of its allele is not surprising. Assuming that the high-acidity $Q$ allele is ancestral to low-acid $q$ allele contributing to increased animal palatability (Ma et al. 2015a; Duan et al. 2017), the seniority, genesis, and DNA sequence differences of $M a-Q_{2}$ and the common $M a-Q$ are yet to be clarified.

Ma3 $-Q_{2}$ had low representation as it was present in just two full-sib families that also showed distorted segregation. Therefore, its discovery was at risk of being false, being due to the coincidental more than usual presence of phenotypic outliers. Confirmation on it being true comes from its colocalization with a QTL of relatively small effect reported by Kenis et al. (2008). That reported result can now be explained by both parents in that study being $Q_{2} q$ rather than $q q$, thus having a smaller phenotypic contrast between the QTL's segregating alleles than would $Q q$ parents. Like $\mathrm{W} 1$ in the present study that inherited the Ma3- $Q_{2}$ allele from 'McIntosh,' the mapping family's parent 'Telamon' in Kenis et al. (2008) is also a (direct) 'McIntosh' descendant and the allele it inherited from 'McIntosh' was determined by us, using FruitBreedomics SNP data (results not shown), to be IBD with the W1 allele. Similarly, the second allele of 'Telamon' inherited from 'Crimson Golden' through 'Golden Delicious' was part of haplotype E-ma3 (Table 3). The existence of multiple degrees of $Q$-allele effects that were well represented in the present study's germplasm could explain why FlexQTL ${ }^{\mathrm{TM}}$ was not able to reach convergence in its QTL genotype estimates for $\mathrm{W} 1$ in some runs for 2010.

Use of the IBD approach (Bink et al. 2014) might be useful to infer QTL genotypes of other breeding parents, ancestors, and founders that are genetically related to our currently examined important breeding parents. Such inferences would help extend QTL genotyping results on specific germplasm to wider germplasm. Comparisons among QTL studies could provide insights into the robustness of QTL effects across genetic backgrounds and environments. For example, the presence of a $M a 3-Q_{2}$ allele in our study was consistent with another QTL mapping study (Kenis et al. 2008) on germplasm that had a common founder origin of the favorable QTL allele. In addition to confirmations, we also noticed some inconsistencies.

Our data allowed complete QTL genotyping of 'Jonathan' and 'Golden Delicious,' two major founders in apple breeding worldwide. These founders were predicted to be heterozygous for $M a$ and homozygous $q q$ for Ma3. In contrast, Ma seemed not to segregate in studies of a 'Jonathan' $\times$ 'Golden Delicious' full-sib family with acidity measured as malate content via HPLC, whereas a QTL was found for Ma3 segregating from 'Jonathan' (Zhang et al. 2012; Sun et al. 2015; Jia et al. 2018). Assuming the 'Jonathan' used in these studies was true-to-type, and if titratable acidity and HPLCassessed malate content are equivalent for apple fruit, then the effect of Ma3 might be sensitive to environmental factors and/ or genetic background.

\section{Diagnostic markers and causal genes}

Two or more of the available SNP markers for each locus would be required to diagnose the alleles present in any individual. For the $M a$ locus, the SNP marker ss475882553 (GDsnp01588) was predictive for $Q / q$ from ten of the eleven ancestral sources. Its predictiveness is further confirmed by consistency of its QTL genotypes in parents of reported QTL studies on acidity. For example, 'Braeburn,' 'Discovery,' 'Fiesta,' 'Prima,' and 'Telamon' were reported to be heterozygous at $M a$ (Maliepaard et al. 1998; Liebhard et al. 2003; Kenis et al. 2008) and were all heterozygous for this marker (in the present dataset or that of FruitBreedomics). Only for 'Duchess of Oldenburg' and derived germplasm carrying the $Q_{2}$ allele from this source was ss 475882553 not predictive. However, the nearby SNP marker ss 475881815 alone discriminated this rare $Q$-allele source. Statements on its predictiveness in segregating families require insights on its distance from the actual gene to which this $Q_{2}$ allele belongs. If this would indeed be the $A L M T 1$ gene of $M a$, the physical distance is more than $3 \mathrm{Mb}$, suggesting a genetic distance of approximately $7 \mathrm{cM}$. Also, further information on the strength of the currently found association would be required prior to its application on wider germplasm.

The reported causal polymorphism for $M a / m a$ is based on an intragenic SNP creating a truncated, ineffective protein for the $m a$ allele, providing the basis for a functional diagnostic DNA marker (Ma et al. 2015b; Jia et al. 2018). However, it does not appear that 'Duchess of Oldenburg' or its descendants were included in the study that identified that causal mutation, allowing for the possibility that this cultivar carries a different mutation at the $M a$ locus or in a nearby gene such as the Ma2 gene described by Bai et al. (2012). Because none of the current single SNP markers at the Ma3 locus were predictive for any $Q / q$ source across the germplasm (they were only predictive within families), extrapolating the $Q / q$ status of $M a$ locus alleles across germplasm requires consideration of multiple SNPs at once, i.e., haplotypes.

Sun identified 194 genes on the GD 1.0 draft genome sequence corresponding to the LG 8 QTL found in 'Jonathan' $\times$ 'Golden Delicious,' and performed some initial candidate gene expression studies. Results from qPCR, complementation, transient expression, and protein studies reported by Jia et al. (2018), continuing the work of Sun et al. (2015), gave insight into the gene networks and signaling pathways involved in vacuolar malic acid content: $M d P P 2 C H$ inactivated 
three vacuolar H+-ATPases that serve as proton pumps across the tonoplast (MdVHA-A3, MdVHA-B2, and MdVHA-D2) as the aluminum-activated malate transporter MdALMTII. Also, $M d P P 2 C H$ was determined to be suppressed by the early auxin response gene, MdSAUR37. Jia et al. (2018) focused on QTL LG 8 co-localizing genes that showed the highest differential segregation between two bulks of high- and low-malate offspring and prioritized genes that were segregating in both the parents 'Jonathan' and 'Golden Delicious,' despite the LG 8 QTL segregating in 'Jonathan' only. These prioritized genes showed a distorted ratio of zygotic genotypes among the 246 randomly chosen offspring of 'Jonathan' $\times$ 'Golden Delicious.' For example, their $M d P P 2 C H$ marker showed a $A A: A G: G G$ segregation of $82: 97: 67$, a significant deviation from the expected 1:2:1 ratio $(p=0.002)$, and showed a significant lack of heterozygotes $(p=0.005)$. The presence of distorted segregation for the LG 8 QTL region in the randomly chosen offspring indicates the presence of selection pressure against certain alleles or zygotes. Depending on how this selection-sensitive trait co-segregated with malate content, the differential segregation between the bulks might have arisen not only from artificial selection for contrasting malate content. This feature might make the bulked segregant analysis approach that was used ineffective for the intended purpose. An alternative, efficient way to identify candidate genes and develop predictive markers for Ma3 might be selective phenotyping and intense genotyping of offspring with recombination in the QTL interval. Segregation distortions in the randomly chosen offspring might indicate the presence of lethal alleles (Gao and van de Weg, 2006). If true, the observed zygotic genotype ratio was consistent with biparental segregation of a single, recessive, lethal allele for a locus located approximately $10 \mathrm{cM}$ from the LG 8 QTL, for which the lethal allele of 'Jonathan' was in coupling phase with the $Q$-allele for malate content (data not shown).

\section{Limitations in this study}

This study observed and managed large experimental variation in the phenotypic data. While TA content generally decreased during storage, some samples showed a large increase of up to $3.7 \mathrm{mg} / \mathrm{L}$. Also, individuals could show large differences between years in TA at harvest. Such phenomena have not been reported in previous QTL mapping studies, which might indicate previous ignorance or the presence here of a more than usual level of experimental error. Curation for extreme outliers improved the between-year correlations, although still only to moderate levels (Online Resources 3, 4, 5 , and 8), probably leaving considerable experimental variation in the genetic analyses. This residual variation might explain the variability in the observed mode and interval size of the QTLs and in the parental QTL genotype estimates among storage treatments and years (Fig. 2, Online Resource 13). The presence of outliers might raise uncertainty on the true presence of multiple $Q$ alleles, especially for $M a 3$ as its discovery was based on a low number of offspring. In that respect, it was useful that our findings on $M a 3-Q_{2}$ were consistent with previous research of Kenis et al. (2008).

Another limitation was in the bi-allelic nature of the QTL models used in QTL mapping. In the presence of multiple $Q$ alleles of different effect, FlexQTL ${ }^{\mathrm{TM}}$ could be wrong in its $Q$ vs. $q$ designations. The presence in the germplasm of more than one kind of high-acidity $Q$ allele for $M a$ and $M a 3$, with quantitatively differing effects for each, might have contributed to the software's inability to determine consistent QTL genotype estimates for certain parents and might have led to incorrectly designated alleles for others. For example, the presence of the $\mathrm{Ma}-\mathrm{Q}_{2}$ allele in 'Honeycrisp' might have hindered FlexQTL TM's ability to accurately designate $Q$ vs. $q$ alleles for that cultivar for both QTLs. This possible issue had only a minor role in our study. A co-factor analyses with SNP ss475882553 as a co-factor representing $\mathrm{Ma}-Q_{2}$ did not affect the previous consensus QTL genotypes - with one exception (Online Resource 18). Previously, W1 was assigned Ma3-qq, whereas in the co-factor analyses results were inconclusive: estimates were inconsistent between years and even within a single simulation (2012-10wk, R2, Online Resource 18). Accounting for the higher-than-high-acidity $M a-Q_{2}$ allele increased awareness of QTL genotype assignment issues with W1, which we can now understand from the presence of a less-strong $\mathrm{Ma} 3-Q_{2}$ allele in this selection.

While the previous two limitations related to confidence in the discovered QTL models, a third limitation relates to obtaining practical insight from the implications of our QTL model. Under-representation in some parts of the compound QTL genotypes (Online Resources 19 and 20) hampers strong conclusions on the performance of QTLs across wide germplasm. Under-representation is true for most QTL mapping studies on a multi-locus trait. In our study, classes with three to four $Q$-doses were mostly under-represented. This outcome is readily expected from binomial probability. Assuming regular segregation and a balanced representation of QTL genotypes across the parent pairs, the class of smallest sample size theoretically holds $1 / 16(6.3 \%)$ and $1 /$ $81(1.2 \%)$ of the total population in the case of a bi-allelic or tri-allelic two-locus trait, respectively. With a population size of around 160 phenotyped offspring per dataset such as in our study, such a class would hold 10 and 2 offspring, respectively. In addition, QTL genotypes are usually not equally distributed over parent pairs and sampling errors occur also, increasing chances for genotype classes with no or very low representation. However, because of obtained insights on effects of trait loci, numbers of alleles, and parental QTL genotypes, directed crosses can now be made for future studies to examine the effects of particular compound QTL genotypes. 


\section{Q-allele dosage model of apple fruit acidity}

The presence of just two major QTLs and the consideration of just two alleles per locus provided a simplified interpretation of fruit acidity genetic control that might lend itself to easy integration into routine breeding decisions. The largely additive genetic variation, compared to relatively low dominance and epistasis, and the similar-sized effects of the two QTLs, as observed for the $\mathrm{H}$ and $10 \mathrm{wk}$ evaluations, indicated that the dosage of high-acidity alleles could be a simple way to understand effects of the two loci. In this model, as long as high-acidity alleles can be distinguished and counted for any individual, there is no need to consider the particular allelic combinations. Some interesting features arose from this model, displayed in Fig. 3. First, at harvest were observed the largest phenotypic distinctions among Ma-Ma3 compound genotypes, which went along with the highest broad- and narrow-sense heritability estimates (Table 1). Second, the higher the $Q$-allele dosage the greater the acidity depletion with storage. This phenomenon indicates physiological limitations of fruit acidity maintenance over long periods of storage, and has breeding implications. As organic acids are considered an energy source for fruit metabolism during storage (Etienne et al. 2013), the greater acidity depletion in fruit of cultivars with higher $Q$-allele dosage might mean that high levels of titratable acidity are depleted at the expense of other energy reserves. Third, the order of QTL genotypes for TA content remained the same during the examined storage period: no crossing regression lines. Therefore, fruit acidity after storage appears to be a function of acidity at harvest, which itself could be explained as a function of $Q$ allele dosage.

The apparent baseline of fruit acidity reached after extended storage of fruit that was indicated by extrapolating beyond the experimentally observed results for each compound genotype has important implications, if true. If indeed TA decreases linearly over time in storage, all genotypes were predicted to eventually reach the same level after about 912 months, with QTL genotype no longer influencing fruit acidity. Fluctuations over the 3 years in the rate of loss and storage time to reach the baseline might be due to particular pre-harvest conditions experienced each year by the trees, as they were all grown at the same location. These observations imply that TA measured at harvest for a set of cultivars representing several $Q$-allele dosages could be used to predict acidity loss patterns throughout the subsequent storage season. Further study is warranted to investigate whether fruit acidity decreases linearly with time in storage, and, if so, if the arising predictive relationship that takes advantage of new genetic information on $Q$-allele dosage holds up in evaluations of fruit stored for durations between 2 and 12 months and in germplasm grown at other locations under other conditions over several years. It would also be valuable to identify pre-harvest factors that influence initial acidity levels and final baselines both for prediction purposes and to inform management practices that could help achieve fruit within target acidity levels for as long as possible to extend market life.

\section{Breeding targets for Q-allele dosage}

Our results indicate that breeders can select for particular $Q$ allele dosages to achieve a particular desired level of high acidity after storage - such as doses of $3 \times$ and $4 \times$ to achieve fruit with $5 \mathrm{mg} / \mathrm{L} \mathrm{TA}$ after a $20 \mathrm{wk}$ treatment (Fig. 3a). Similarly, the results indicate that, to avoid acidity being too low, particular $Q$-allele dosages should be avoided — such as $0 \times$ or $1 \times$ doses to avoid fruit with less than $3.5 \mathrm{mg} / \mathrm{L} \mathrm{TA}$ after a 20wk treatment (Fig. 3a). As acidity levels of $>5 \mathrm{mg} / \mathrm{L}$ are generally considered desirable for apple fruit (Harker et al. 2008) and most apple fruit consumed are subject to several months of storage, a breeding target of 3-4 $Q$ alleles might appear to be feasible. However, there are several arguments against that strategy. First, the acidity associated with such fruit is expected to be unpalatable at harvest. Second, the relatively rapid depletion of acidity in storage of these highest $Q$-allele dosages would be expected to be associated with an inconsistent perceived flavor over time, which could confuse consumers. Third, the rapid depletion of acidity would be expected to be associated with the shortest time within the desired range, and thus the shortest market life. Indeed, breeders appear to have avoided such a strategy as all nine important breeding parents in the present study carried only one or two $Q$ alleles. And, from our observations over wider germplasm, few if any cultivars and selections, from heritage to modern, appear to have more than two $Q$ alleles. Besides too many $Q$ alleles, zero $Q$ alleles with its associated bland flavor also appear to have been completely avoided in apple cultivar development. Because of the high frequency and multiple sources of $Q$ and $q$ alleles for both QTLs, there are numerous ways that breeders are able to achieve the desired number of $Q$ alleles in new cultivar development. Finetuning of the Q-allele dosage model to account for some epistasis between the two loci and effects of alternative $\left(Q_{2}\right)$ alleles could further improve the explanatory power of the $Q$-allele dosage model.

\section{Data archiving statement}

Genotypic data (1344 filtered SNP markers) of the multifamily germplasm set investigated has been submitted to the Genome Database for Rosaceae (www.rosaceae.org). 
Acknowledgements Dr. Luis F. Osorio provided helpful guidance with ASReml statistical analysis, and Lichun Cai and Stijn Vanderzande helped curate raw SNP data. Jack Klipfel conducted laboratory analyses for Ma1-SNP1455. Some genetic data and technical expertise came from the FruitBreedomics project no 265582: "Integrated approach for increasing breeding efficiency in fruit tree crops" (www.fruitbreedomics.com), which was co-funded by the EU seventh Framework Programme.

Funding information This work was funded by the USDA's National Institute of Food and Agriculture (NIFA)-Specialty Crop Research Initiative projects "RosBREED: Enabling marker-assisted breeding in Rosaceae" (2009-51181-05808) and "RosBREED: Combining disease resistance with horticultural quality in new rosaceous cultivars" (201451181-22378), and USDA NIFA Hatch projects 0211277 and 1014919.

Open Access This article is distributed under the terms of the Creative Commons Attribution 4.0 International License (http:// creativecommons.org/licenses/by/4.0/), which permits unrestricted use, distribution, and reproduction in any medium, provided you give appropriate credit to the original author(s) and the source, provide a link to the Creative Commons license, and indicate if changes were made.

Publisher's note Springer Nature remains neutral with regard to jurisdictional claims in published maps and institutional affiliations.

\section{References}

Bai Y, Dougherty L, Li M, Fazio Z, Cheng L, Xu K (2012) A natural mutation-led truncation in one of the two aluminum-activated malate transporter-like genes at the $M a$ locus is associated with low fruit acidity in apple. Mol Gen Genomics 287:663-678

Baojiang L, Guiyong L, Shixi J (1995) Studies on the inheritance and selection of sweetness and acidity of apples. Acta Hortic 403:233240

Beach SA, Booth NO, Taylor OM (1905) Apples of New York (Vol II) State of New York - Department of Agriculture. J. B. Lyon Company, New York, pp 150-152

Bianco L, Cestaro A, Sargent DJ, Banchi E, Derdak S, Di Guardo N, Salvi S, Viola R, Gut I, Laurens F, Chagné D, Velasco R, van de Weg E, Troggio M (2014) Development and validation of a 20K Single Nucleotide Polymorphism (SNP) whole genome genotyping array for apple (Malus $\times$ domestica Borkh). PLoS ONE 9: e110377

Bink MCAM, Uimari P, Sillanpaa J, Janss LLG, Jansen RC (2002) Multiple QTL mapping in related plant populations via a pedigreeanalysis approach. Theor Appl Genet 104:751-762

Bink MCAM, Totir LR, ter Braak CJF, Winkler CR, Boer MP, Smith OS (2012) QTL linkage analysis of connected populations using ancestral marker and pedigree information. Theor Appl Genet 124:10971113

Bink MCAM, Jansen J, Madduri M, Voorrips RE, Durel C-E, Kouassi AB, Laurens F, Mathis F, Gessler C, Gobbin D, Rezzonico F, Patocchi A, Kellerhals M, Boudichevskaia A, Dunemann F, Peil A, Nowicka A, Lata B, Stankiewicz-Kosyl M, Jeziorek K, Pitera E, Soska A, Tomala K, Evans KM, Fernández-Fernández F, Guerra W, Korbin M, Keller S, Lewandowski M, Plocharski W, Rutkowski K, Zurawicz E, Costa F, Sansavini S, Tartarini S, Komjanc M, Mott D, Antofie A, Lateur M, Rondia A, Gianfranceschi L, van de Weg WE (2014) Bayesian QTL analyses using pedigreed families of an outcrossing species, with application to fruit firmness in apple. Theor Appl Genet 127:1073-1090

Chagné D, Crowhurst RN, Troggio M, Davey MW, Gilmore B, Lawley C, Vanderzande S, Hellens RP, Kumar S, Cestaro A, Velasco R, Main D, Rees J, Iezzoni A, Mockler T, Wilhelm L, van de Weg E,
Gardiner SE, Bassil N, Peace C (2012a) Genome-wide SNP detection, validation, and development of an $8 \mathrm{~K}$ SNP array for apple. PLoS One 7:e31745

Chagné D, Krieger C, Rassam M, Sullivan M, Fraser J, André C, Pindo M, Troggio M, Gardiner SE, Henry RA, Allan AC, McGhie TK, Laing WA (2012b) QTL and candidate gene mapping for polyphenolic composition in apple fruit. BMC Plant Biol 12:12

Chagné D, Vanderzande S, Kirk C, Profitt N, Weskett R, Gardiner SE, Peace CP, Volz RK, Bassil NV (2019) Validation of SNP markers for fruit quality and disease resistance loci in apple (Malus $\times$ domestica Borkh.) using the OpenArray platform. Hortic Res (in press)

Cliff MA, Stanich K, Lu R, Hampson CR (2016) Use of descriptive analysis and preference mapping for early-stage assessment of new and established apples. J Sci Food Agric 96:2170-2183

Costa e Silva J, Borralho NMG, Potts BM (2004) Additive and nonadditive genetic parameters from clonally replicated and seedling progenies of Eucalyptus globulus. Theor Appl Genet 108:11131119

Costa F, van de Weg WE, Stella S, Dondini L, Pratesi D, Musacchi S, Sansavin S (2008) Map position and functional allelic diversity of $M d-\operatorname{Exp} 7$, a new putative expansin gene associated with fruit softening in apple (Malus $\times$ domestica Borkh.) and pear (Pyrus communis). Tree Genet Genomes 4:575-586

Crane MB, Lawrence WJC (1934) Genetical studies in cultivated apples. J Genetics 265-296

Daccord N, Celton JM, Linsmith G, Becker C, Choisne N, Schijlen E, van de Geest H, Bianco L, Muranty H, Micheletti D, Di Pierro EA, Gouzy J, Gaillard S, Velasco R, Durel CE, Rees DJG, Laurens F, Lespinasse Y, Quesneville H, Aubourg S, Weigel D, van de Weg E, Troggio M, Bucher E (2017) High-quality de novo assembly of the apple genome and methylome dynamics of early fruit development. Nat Genet 49:1099-1106

Di Guardo M, Micheletti D, Bianco L, Koehorst-van Putten HJ, Longhi S, Costa F, Aranzana MJ, Velasco R, Arús P, Troggio M, van de Weg EW (2015) ASSIsT: an automatic SNP scoring tool for in- and outbreeding species. Bioinformatics 31:3873-3874

Di Pierro EA, Gianfranceschi L, Di Guardo M, Koehorst - van Putten HJJ, Kruisselbrink JW, Longhi S, Troggio M, Bianco L, Muranty H, Pagliarani G, Tartarini S, Letschka T, Lozano-Luis L, GarkavaGustavsson L, Micheletti D, Bink MCAM, Voorrips RE, Aziz E, Velasco R, Laurens F, van de Weg E (2016) A highdensity, multiparental SNP genetic map on apple validates a new mapping approach for outcrossing species. Hortic Res 3:16057

Dove WF, Murphy E (1936) The vitamin C-content of apples and its relation to human welfare. Science 83:325-327

Duan N, Bai Y, Sun H, Wang N, Ma Y, Li M, Wang X, Jiao C, Legall N, Mao L, Wan S, Wang K, He T, Feng S, Zhang Z, Mao Z, Shen X, Chen X, Jiang Y, Wu S, Yin C, Ge S, Yang L, Jiang S, Xu H, Liu J, Wang D, Qu C, Wang Y, Zuo W, Xiang L, Liu C, Zhang D, Gao Y, Xu Y, Xu K, Chao T, Fazio G, Shu H, Zhong G-Y, Cheng L, Fei Z, Chen X (2017) Genome re-sequencing reveals the history of apple and supports a two-stage model for fruit enlargement. Nature Communications 8(1):249. https://doi.org/10.1038/s41467-01700336-7

Etienne A, Génard M, Lobit P, Mbeguié-A-Mbéguié D, Bugaud C (2013) What controls fleshy fruit acidity? A review of malate and citrate accumulation in fruit cells. J Exp Bot 64:1451-1469

Evans K (2013) Apple breeding in the Pacific Northwest. Acta Hort 976: $75-78$

Evans K, Guan Y, Luby J, Clark M, Schmitz C, Brown S, Orcheski B, Peace C, van de Weg E, Iezzoni A (2012) Large-scale standardized phenotyping of apple in RosBREED. Acta Hortic 945:233-238

Gao Z, van de Weg WE (2006) The $V f$ gene for scab resistance in apple is linked to sub-lethal genes. Euphytica 151:123-132

Harker FR, Lau K, Gunson FA (2003) Juiciness of fresh fruit: a timeintensity study. Postharvest Biol and Technol 29:55-60 
Harker FF, Kupferman EM, Marin AB, Gunson FA, Triggs FM (2008) Eating quality standards for apples based on consumer preferences. Postharvest Biol Technol 50:70-78

Haynes D (1925) Chemical studies in the physiology of apples I. Change in the acid content of stored apples and its physiological significance. Ann Bot 1:77-96

Howard NP, van de Weg E, Bedford DS, Peace C, Vanderzande S, Clark MD, Teh SL, Cai L, Luby JJ (2017) Elucidation of the 'Honeycrisp' pedigree through haplotype analysis with a multi-family integrated SNP linkage map and a large apple (Malus $\times$ domestica) pedigreeconnected SNP data set. Hortic Res 4:17003

Howard NP, van de Weg E, Tillman J, Tong CBS, Silverstein KAT, Luby J (2018) Two QTL characterized for soft scald and soggy breakdown in apple (Malus $\times$ domestica) through pedigree-based analysis of a large population of interconnected families. Tree Genet Genomes 14:2

Hu DG, Sun CH, Ma QJ, You CX, Cheng L, Hao YJ (2016) MdMYB1 regulates anthocyanin and malate accumulation by directly facilitating their transport into vacuoles in apples. Plant Physiol 170:13151330

Hu DG, Li YY, Zhang QY, Li M, Sun CH, Yu JQ, Hao YJ (2017) R2R3MYB transcription factor MdMYB73 is involved in malate accumulation and vacuolar acidification in apple. Plant J 91:443-454

Iezzoni A, Weebadde C, Luby J, Chengyan Y, van de Weg E, Fazio G, Main D, Peace C, Bassil N, McFerson J (2010) RosBREED: enabling marker-assisted breeding in Rosaceae. Acta Hort 859:389394

Iwanami H, Moriya S, Kotoda N, Takahashi S, Abe K (2008) Storability in cold temperatures can be evaluated based on changes in fruit quality in apple genotypes under shelf life conditions. HortScience 43:655-660

Iwanami H, Moriya S, Kotoda N, Mimida N, Takahashi-Sumiyoshi S, Abe K (2012) Mode of inheritance in fruit acidity in apple analysed with a mixed model of a major gene and polygenes using large complex pedigree. Plant Breed 131:322-328

Jia D, Shen F, Wang Y, Wu T, Xu X, Zhang X, Han Z (2018) Apple fruit acidity is genetically diversified by natural variations in three hierarchical epistatic genes: MdSAUR37, MdPP2CH and MdALMTII. Plant J 95:427-443

Jung S, Ficklin SP, Lee T, Cheng C-H, Blenda A, Zheng P, Yu J, Bombarely A, Cho I, Ru S, Evans K, Peace C, Abbott AG, Mueller LA, Olmstead MA, Main D (2014) The Genome Database for Rosaceae (GDR): year 10 update. Nucleic Acids Res 42:D1237-D1244

Kass RE, Raftery AE (1995) Bayes factors. J Am Stat Assoc 90(430): 773-795

Kenis K, Keulemans J, Davey M (2008) Identification and stability of QTLs for fruit quality traits in apple. Tree Genet Genomes 4:647661

Khan SA, Beekwilder J, Schaart JG, Mumm R, Soriano JM, Jacobsen E, Schouten HJ (2013) Differences in acidity of apples are probably mainly caused by a malic acid transporter gene on LG16. Tree Genet Genomes 9:475-487

King GJ, Maliepaard C, Lynn JR, Alston FH, Durel C-E, Evans KM, Griffon B, Laurens F, Manganaris AG, Schrevens E, Tartarini S, Verhaegh J (2000) Quantitative genetic analysis and comparison of physical and sensory descriptors relating to fruit flesh firmness in apple (Malus pumila Mill.). Theor Appl Genet 100:1074-1084

King GJ, Lynn JR, Dover CJ, Evans KM, Seymour GB (2001) Resolution of quantitative trait loci for mechanical measures accounting for genetic variation in fruit texture of apple (Malus pumila Mill.). Theor Appl Genet 102:1227-1235

Kouassi AB, Durel CE, Fabrizio C, Tartarini S, Van de Weg E, Evans K, Fernandez-Fernandez F, Govan C, Boudichevskaja A, Dunemann F, Antofie A, Lateur M, Stankiewicz-kosyl M, Soska A, Tomala K, Lewandowski M, Rutkovski K, Zurawicz E, Walter G, Laurens F
(2009) Estimation of genetic parameters and prediction of breeding values for apple (Malus $x$ domestica) fruit quality traits using pedigreed plant material in Europe. Tree Gen Genomes 5:659-672

Kumar S, Chagne D, Bink MC, Volz RK, Whitworth C, Carlisle C (2012) Genomic selection for fruit quality traits in apple (Malus $\mathrm{x}$ domestica Borkh.). PLoS One 7:e36674

Laurens F, Durel CE, Patocchi A, Peil A, Salvi S, Tartarini S, Velasco R, van de Weg E (2010) Review on apple genetics and breeding programmes and presentation of a new European initiative to increase fruit breeding efficiency. J Fruit Sci 27:102-107

Laurens F, Aranzana MJ, Arus P, Bassi D, Bink M, Bonany J, Caprera A, Corelli-Grappadelli L, Costes E, Durel CE, Mauroux JB, Muranty H, Nazzicari N, Pascal T, Patocchi A, Peil A, Quilot-Turion B, Rossini L, Stella A, Troggio M, Velasco R, van de Weg E (2018) An integrated approach for increasing breeding efficiency in apple and peach in Europe. Hortic Res 5:11

Liebhard R, Gianfranceschi L, Koller B, Ryder CD, Tarchini R, van de Weg WE, Gessler (2002) Development and characterisation of 140 new microsatellites in apple (Malus $x$ domestica Borkh). Mol Breed 10:217-241

Liebhard R, Koller B, Gianfranceschi L, Gessler C (2003) Creating a saturated reference map for the apple (Malus $\times$ domestica Borkh.) genome. Theor Appl Genet 106:1497-1508

Ma B, Chen J, Zheng H, Fang T, Ogutu C, Li S, Han Y, Wu B (2015a) Comparative assessment of sugar and malic acid composition in cultivated and wild apples. Food Chem 172:86-91

Ma B, Liao L, Zheng H, Chen J, Wu B, Ogutu C, Li S, Korban SS, Han Y (2015b) Genes encoding aluminum-activated malate transporter II and their association with fruit acidity in apple. Plant Genome 8:0

Ma BQ, Zhao S, Wu BH, Wang D, Peng Q, Owiti A, Fang T, Liao L, Ogutu C, Korban SS, Li S, Han Y (2016) Construction of a high density linkage map and its application in the identification of QTLs for soluble sugar and organic acid components in apple. Tree Genet Genomes 12:1

Maliepaard C, Alston FH, van Arkel G, Brown LM, Chevreau E, Dunemann F, Evans KM, Gardiner S, Guilford P, van Heusden AW, Janse J, Laurens F, Lynn JR, Manganaris AG, den Nijs APM, Periam N, Rikkerink E, Roche P, Ryder C, Sansavini S, Schmidt H, Tartarini S, Verhaegh JJ, Vrielink-van Ginkel M, King GJ (1998) Aligning male and female linkage maps of apple (Malus pumila Mill.) using multi-allelic markers. Theor Appl Genet 97:60-73

Mangandi J, Verma S, Osorio L, Peres NA, van de Weg E, Whitaker VM (2017) Pedigree-based analysis in a multiparental population of octoploid strawberry reveals QTL alleles conferring resistance to Phytophthora cactorum. G3: Genes Genom Genet 7:1707-1719

Martinoia E, Maeshima M, Neuhaus HE (2007) Vacuolar transporters and their essential role in plant metabolism. J Exp Bot 58:83-102

Nybom N (1959) On the inheritance of acidity in cultivated apples. Hereditas 45:332-350

Peace CP, Luby J, van de Weg E, Bink M, Iezzoni AF (2014) A strategy for developing representative germplasm sets for systematic QTL validation, demonstrated for apple, peach and sweet cherry. Tree Genet Genomes 10:1679-1694

Pikunova A, Madduri M, Sedov E, Noordijk Y, Peil A, Troggio M, Bus VGM, van de Weg E (2013) 'Schmidt's Antonovka' is identical to 'Common Antonovka', an apple cultivar widely used in Russia in breeding for biotic and abiotic stresses. Tree Genet Genomes 10: 261-271

Rouchaud L, Moons C, Meyer JA (1985) Cultivar differences in the influence of harvest date and cold storage on the free sugar and acids contents, and the eating quality of apples. J Hortic Sci Biotech 60 : 291-296

Silfverberg-Dilworth E, Matasci CL, van de Weg WE, Van Kaauwen MPW, Walser M, Kodde LP, Soglio V, Gianfranceschi L, Durel CE, Costa F, Yamamoto T, Koller B, Gessler C, Patochhi A 
(2006) Microsatellite markers spanning the apple (Malus $\mathrm{x}$ domestica Borkh.) genome. Tree Genet Genomes 2:202-224

Sun R, Chang YS, Yang FQ, Wang Y, Li H, Zhao YB, Chen DM, Wu T, Zhang XZ, Han ZH (2015) A dense SNP genetic map constructed using restriction site-associated DNA sequencing enables detection of QTLs controlling apple fruit quality. BMC Genomics 16:747

Sweetman C, Deluc LG, Cramer GR, Ford CM, Soole KL (2009) Regulation of malate metabolism in grape berry and other developing fruits. Phytochemistry 70:1329-1344

van de Weg WE, Voorrips RE, Finkers HJ, Kodde LP, Jansen J, Bink MCAM (2004) Pedigree genotyping: a new pedigree-based approach of QTL identification and allele mining. Acta Hortic 663: $45-50$

van de Weg E, Di Guardo M, Jänsch N, Socquet-Juglard D, Costa F, Baumgartner I, Broggini GAL, Kellerhals M, Troggio M, Laurens F, Durel CE, Patocchi A (2018) Epistatic fire blight resistance QTL alleles in the apple cultivar 'Enterprise' and selection X-6398 discovered and characterized through pedigree-informed analysis. Mol Breed 38:5

Velasco R, Zharkikh A, Affourtit J, Dhingra A, Cestaro A, Kalyanaraman A, Fontana P, Bhatnagar SK, Troggio M, Pruss D, Salvi S, Pindo M, Baldi P, Castelletti S, Cavaiuolo M, Coppola G, Costa F, Cova V, Dal Ri A, Goremykin V, Komjanc M, Longhi S, Magnago P, Malacarne G, Malnoy M, Micheletti D, Moretto M, Perazzolli M, Si-Ammour A, Vezzulli S, Zini E, Eldredge G, Fitzgerald LM, Gutin N, Lanchbury J, Macalma T, Mitchell JT, Reid J, Wardell B, Kodira C, Chen Z, Desany B, Niazi F, Palmer M, Koepke T, Jiwan D, Schaeffer S, Krishnan V, Wu C, Chu VT, King ST, Vick J, Tao Q, Mraz A, Stormo A, Stormo K, Bogden R, Ederle D, Stella A, Vecchietti A, Kater MM, Masiero S, Lasserre P, Lespinasse Y,
Allan AC, Bus V, Chagné D, Crowhurst RN, Gleave AP, Lavezzo E, Fawcett JA, Proost S, Rouzé P, Sterck L, Toppo S, Lazzari B, Hellens RP, Durel CE, Gutin A, Bumgarner RE, Gardiner SE, Skolnick M, Egholm M, van de Peer Y, Salamini F, Viola R (2010) The genome of the domesticated apple (Malus $\times$ domestica Borkh.). Nat Genet 42:833-839

Visser T, Verhaegh JJ (1978) Inheritance and selection of some fruit characters of apple. I. Inheritance of low and high acidity. Euphytica 27:753-760

Voorrips RE (2002) MapChart: software for the graphical presentation of linkage maps and QTLs. J Hered 93:77-78

Voorrips RE, Bink MCAM, Kruisselbrink JW, Koehorst-van Putten HJJ, van de Weg WE (2016) PediHaplotyper: software for consistent assignment of marker haplotypes in pedigrees. Mol Breed 36:119

Watkins CB (2017) Advances in post-harvest storage and handling of apples. In: Evans K (ed) Achieving sustainable cultivation of apples. Burleigh Dodds, Cambridge, pp 337-370

Wellington R (1924) An experiment in breeding apples. II. - New York State Agr. Exp. Sta. Techn. Bull. No. 106. 149 pp

Xu K, Wang A, Brown S (2012) Genetic characterization of the Ma locus with pH and titratable acidity in apple. Mol Breed 30:899-912

Zhang YZ, Li PM, Cheng LL (2010) Developmental changes of carbohydrates, organic acids, amino acids, and phenolic compounds in 'Honeycrisp' apple flesh. Food Chem 123:1013-1018

Zhang Q, Ma BQ, Li H, Chang Y, Han Y, Li J, Wei G, Zhao S, Khan MA, Zhou Y, Gu C, Zhang X, Han Z, Korban SS, Li S, Han Y (2012) Identification, characterization, and utilization of genome-wide simple sequence repeats to identify a QTL for acidity in apple. BMC Genomics 13:537 